Portland State University

PDXScholar

Winter 3-7-2013

\title{
An Experimental Investigation of Nest Reuse and Nest Site Selection in an Open-Cup Nesting Passerine
}

Sarah A. Cancellieri

Portland State University

Follow this and additional works at: https://pdxscholar.library.pdx.edu/open_access_etds

Part of the Ornithology Commons, and the Zoology Commons

Let us know how access to this document benefits you.

Recommended Citation

Cancellieri, Sarah A., "An Experimental Investigation of Nest Reuse and Nest Site Selection in an Open-Cup Nesting Passerine" (2013). Dissertations and Theses. Paper 641.

https://doi.org/10.15760/etd.641

This Thesis is brought to you for free and open access. It has been accepted for inclusion in Dissertations and Theses by an authorized administrator of PDXScholar. Please contact us if we can make this document more accessible: pdxscholar@pdx.edu. 
An Experimental Investigation of Nest Reuse and Nest Site Selection in an Open - Cup

Nesting Passerine

by

Sarah A. Cancellieri

A thesis submitted in partial fulfillment of the requirements for the degree of

Master of Science

in

Biology

Thesis Committee:

Michael Murphy, Chair

Luis Ruedas

Pamela Yeh

Portland State University

2013 
(C) 2013 Sarah A. Cancellieri 


\begin{abstract}
Eastern Kingbirds (Tyrannus tyrannus) breed from coast to coast in North America and build open-cup nests in trees. They have been extensively studied across most of their range and have only on occasion been documented to reuse a nest from a previous season. However, at Malheur National Wildlife Refuge (MNWR), located in southeastern Oregon, $\sim 10 \%$ of female Eastern Kingbirds reuse old nests of mainly American Robins (Turdus migratorius). In an attempt to address why nest reuse is so common at MNWR, I used artificial nests to evaluate two hypotheses as to why nest reuse is common in this breeding population. The first hypothesis states that Eastern Kingbirds reuse nests to save time and/or energy (TES) and the second one states nest reuse occurs because there is a shortage of suitable nest sites (NSS). I was able to reject the TES hypothesis because artificial nests provided no apparent reproductive benefits to Eastern Kingbirds, except that if a nest had failed it took less time to lay a replacement clutch after an initial failure if an artificial nest was used instead of building a new nest. A more reasonable explanation is that Eastern Kingbirds face a limited availability of suitable nest sites. With this in mind, I took vegetation measurements to address the hypothesis that Eastern Kingbirds make adaptive choices when selecting a nest site, in which case they would choose sites that increase their probability of breeding successfully. Successful nests, both natural and artificial, were placed higher in a tree and on a steeper angled nest branch than their failed counterparts. Those findings suggest that Eastern Kingbirds make adaptive choices when selecting a nest site.
\end{abstract}




\section{Dedication}

I dedicate this to my mom and dad. 


\section{ACKNOWLEDGMENTS}

Acknowledgements I would like to thank Dr. Michael Murphy, who provided guidance and help when I needed it. This project would not be possible without him, as he hired me on as a graduate student to complete a project studying Eastern Kingbirds at Malheur National Wildlife Refuge. He helped me make the artificial nests, he steered the canoe when we had to attach the artificial nests to the trees. When the central patrol road was closed to cars Dr. Murphy carried the canoe alone for $5 \mathrm{~km}$. He also provided great assistance with the statistics. I would also like to thank my committee members, Luis Ruedas and Pamela Yeh, for their guidance. This study would not be possible without the cooperation of the staff at Malheur National Wildlife Refuge. We had a place to stay thanks to the Malheur Field Station. I would like to thank my lab mate Chris Chutter who helped me work on my project in 2010 and for the use of his vehicle during the field season. He was great company in the field and we spent many early mornings together mist netting for birds. He also helped me take vegetation measurements and made sure that I did not succumb to heat stroke one hot day. I would also like to thank Mandy Klehr who was my field technician in 2011 and helped me tremendously. She had a great sense of humor, which helped for long hours in the field. My research would not be possible without the funding sources from the Association of Field Ornithologists and the National Science Foundation. A special thanks to Daniel Hassumani for all of his help and support. 


\section{PAGE}

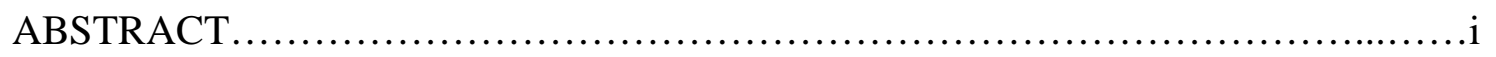

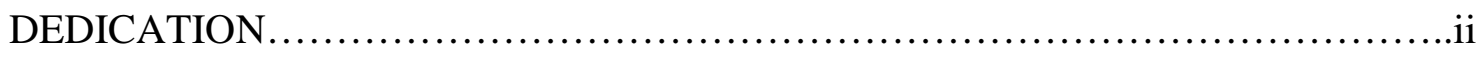

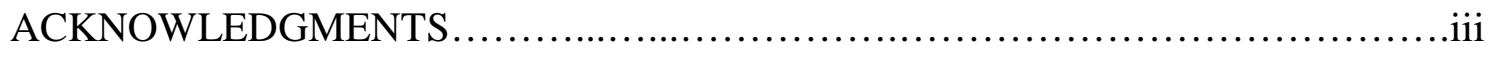

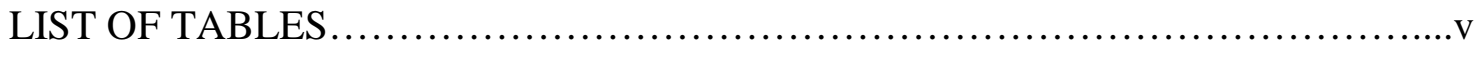

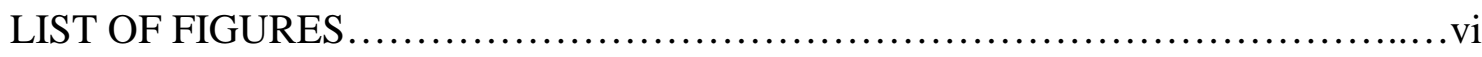

CHAPTER 1: Overview and background.......................................

CHAPTER 2: Experimental examination of nest reuse by an open-cup nesting passerine

Abstract.....................................................................

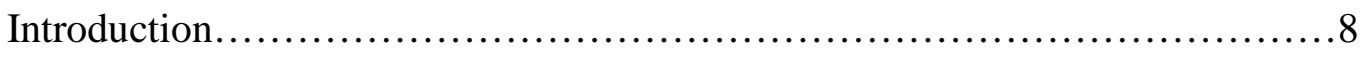

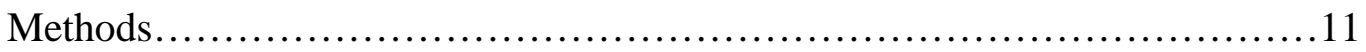

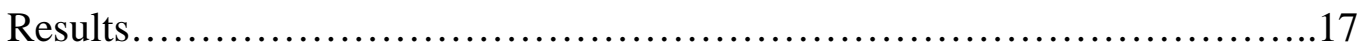

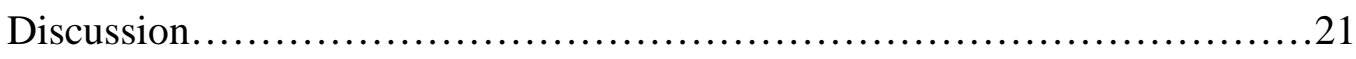

CHAPTER 3: Nest site selection in Eastern Kingbirds

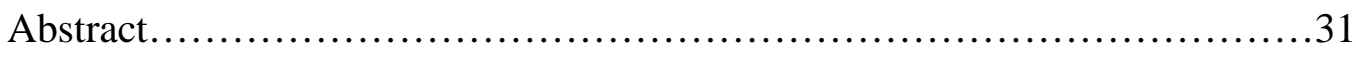

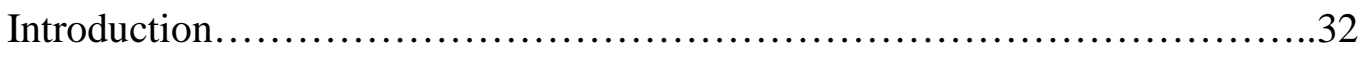

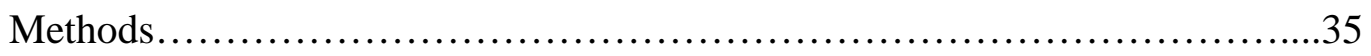

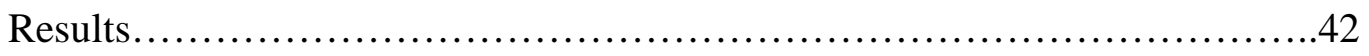

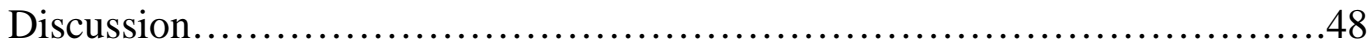

CHAPTER 4: Conclusions...................................................64

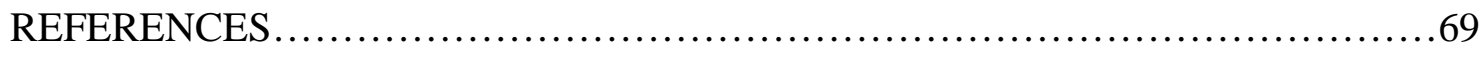




\section{LIST OF TABLES}

\section{PAGE}

TABLE 2.1: Results of reproductive traits of females using a natural or artificial nest.............................................................. 25

TABLE 2.2: Results of General Linear Model of reproductive traits.................26

TABLE 3.1: Nest placement statistics for natural, used and unused artificial nests.....56

TABLE 3.2: Nest placement statistics for failed and successful breeding attempts for natural and artificial nests............................................. 57

TABLE 3.3: Results from a PCA of nest placement variables for natural and used

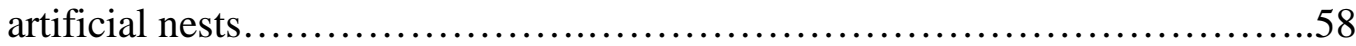

TABLE 3.4: Model selection table summarizing results of the analysis of number of young to fledge $(0-4)$

TABLE 3.5: Variables that contributed to the top models (i.e., AICc < 2.0) of variation in fledging success..............................................60

TALBE 3.6: Model selection table summarizing results of the analysis of number of

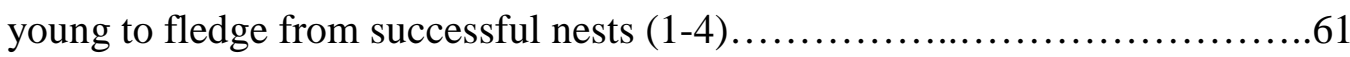




\section{LIST OF FIGURES}

\section{PAGE}

Figure 2.1 Box and whisker plot of the laying date of initial nests for Eastern

Kingbirds.....................................................27

Figure 2.2 Box and whisker plot of the mass of natural and artificial nests...........28

Figure 2.3 Box and whisker plot of the time taken to replace a failed nest............29

Figure 2.4 Photograph of artificial nests attached to willow tree limbs..............30

Figure 3.1 Box-and-whisker plot of PC1 compared to categories of nest success and nest type......................................................62

Figure 3.2 Scatter plot of young fledged and nest cover for years 2010 and $2011 \ldots . .63$ 


\section{CHAPTER 1: OVERVIEW AND BACKGROUND}

This thesis summarizes two years of research on Eastern Kingbirds (Tyrannus tyrannus) at Malheur National Wildlife Refuge, in southeastern Oregon. My research focused on two aspects of the nesting behavior of Eastern Kingbirds by using artificial nests to address (a) why nest reuse is relatively common in this breeding population and (b) if nest site selection is an adaptive behavior. These two studies are presented in detail in the following chapters. In order to better describe the outcomes of these studies, it is important to first provide an overview of the research that has been done in the past that led me to the questions that I have sought to answer. Therefore, I will first start by describing the importance of nests and why nest reuse may be beneficial to birds.

Nests are vitally important for the reproduction of birds because eggs are incubated and young develop in the nest. Nest building is energetically costly and it takes time to build even seemingly simple nests. The costs include but are not limited to a delayed start to nesting (Cavitt et al. 1999; Hauber 2002; Safran 2006), reduced clutch size (Weeks 1978; Eberhardt 1994 in Walters et al. 2002; but see Conrad \& Robertson 1993), and lower seasonal production of young (Hauber 2002; Safran 2006). Because nest building is energetically costly, it would seem practical for birds to reuse a nest if one was available. Secondary cavity nesting birds frequently reuse nests because usable nest sites are limited (Brawn \& Balda 1988; Dobkin et al. 1995; but see Waters \& Noon 1990; reviewed by Newton 1998), whereas open-cup nesting birds build nests that are cup shaped on a branch or the ground. As a consequence, it is assumed that open-cup 
nesters do not face a shortage of suitable nest sites. The risks associated with reusing a nest are high because old nests may harbor ectoparasites (Brown and Brown 1986), nests may be weathered and weak, and nest predators such as corvids may remember the nest's location (Sonerud and Fjeld 1987). However, there are benefits to reusing a nest from previous seasons. For example, less time and/or energy is devoted to building a nest, and a nest in which young were previously fledged may also be likely to result in fledglings in the future (Richmond et al. 2007; Ellison 2008; but see Cavitt et al. 1999; Styrsky 2005).

Eastern Kingbirds (hereafter kingbirds) are Nearctic-Neotropic migrants that breed in North America from coast to coast during the summer months and winter in South America (Murphy 1996a). Male and female kingbirds exhibit high site fidelity (Murphy 1996b), and commonly renest on the same branch in the same nest tree used in prior years (Blancher \& Robertson 1985; Murphy 1996a, 2004). Female kingbirds are primarily responsible for nest site selection and build the nest without male assistance in an average of $7.3 \mathrm{~d}(\mathrm{SE}=0.35, \mathrm{~N}=24$; range $=5$ to $10 \mathrm{~d})$. The materials used to construct the outer wall of the often bulky and conspicuous nests are small twigs, coarse roots, strips of bark, and stems of herbaceous plants, while the distinctive inner lining is composed of finer rootlets and soft materials such as cattail (Typha spp.) down, fine grass stems, and occasionally feathers. Kingbirds exhibit biparental care, but males do not incubate, and make fewer trips to feed nestlings (Woodard and Murphy 1999). On the other hand, males are primarily responsible for nest vigilance and nest defense (Redmond et al. 2009a). Post-fledging parental care lasts 3 to 5 weeks (Morehouse and Brewer 
1968), and as a consequence, kingbirds raise only a single brood $\mathrm{yr}^{-1}$. On average, twothirds of nests fail, due almost entirely to nest predation by corvids. Failed first nesting attempts are almost always replaced by construction of a new nest within $150 \mathrm{~m}$ of the initial nest. Kingbirds are members of the family Tyrannidae, and most tyrannids have a longer nesting cycle (i.e. eggs to independent young) than most other temperate-zone breeding, open-cup nesting passerines (Murphy 1983). The kingbirds breeding at MNWR are unique because they refurbish old nests, and this behavior is rarely seen elsewhere.

Approximately $10 \%$ of kingbirds at MNWR lay clutches in reused nests every year, and they most often use American Robin (Turdus Migratorius) nests (Redmond et al.2007). MNWR is located at the northern end of the Great Basin Desert, at an elevation of $\sim 1,256 \mathrm{~m}$. The onset of breeding by MNWR's kingbirds is delayed compared to other populations because of the delayed onset of summer arising from the high elevation environment. Late nesting at MNWR can thus place further limitations on the length of their nesting season. Because the females at MNWR face a shortage of time to build their nests, it should be beneficial for them to reuse a nest because they could save time and/or energy. The savings in time and/or energy could then be allocated to resources elsewhere, such as laying larger clutches (or eggs), or initiating egg-laying earlier than a female that did not reuse a nest.

Nest reuse may also occur in this breeding population of kingbirds because there is a limited supply of high quality nest sites. The majority of kingbirds nest along the Donner und Blitzen River in young Willow trees (Salix spp.; Redmond et al. 2007), which are spindly and vertically oriented. A high desert habitat surrounds the river and is 
characterized by sagebrush (Artemisia tridentata) and juniper (Juniperus spp.). Over the past 10 years, kingbirds have rarely nested in juniper or sagebrush (Murphy, personal communication). American Robins (Turdus migratorius) and Mourning Doves (Zenaida macroura) also nest syntopically with kingbirds, further limiting the availability of high quality nest sites. I used artificial nests (ARTs) to investigate why nest reuse occurs frequently in kingbirds breeding at MNWR by testing two alternate hypotheses (a) savings of time/energy (TES) and (b) nest site shortage (NSS).

To complement the nest reuse study, I evaluated whether nest success was dependent on nest placement and to describe kingbirds' nest site selection. Nest predation is the principal cause of nest failure for birds (Ricklefs 1969, Martin and Li 1993) and selection of a safe nest site is therefore perceived as a critical behavior contributing to the reproductive success and fitness of birds (Forstmeier and Weiss 2004, Latif et al. 2012). Short-lived birds may have few opportunities to breed over their lifetime and individuals that make poor choices may be eliminated from the gene pool. Therefore, there should be strong selection for safe and secure nest sites. Studies have shown that individuals can modify nest placement in a manner to increase the probability of nest success (Marzluff 1988, Forstmeier and Weiss 2004, Latiff et al. 2012). Birds may also build their nest in thick vegetation to defend it against actively searching predators.

Nest concealment is the first line of defense against actively searching predators and many studies have shown that well concealed nests built in thick vegetation have a reduced risk of nest predation (Colias and Colias 1984, Götmark 1995; but see Howlett and Stutchbury 1996, Holway 1991). Also, nests that are placed higher in trees or shrubs 
may decrease the chance of nest loss (Murphy 1983, Wilson and Cooper 1998, Burhans et al. 2002) because they are safer from ground foraging predators. However, nests located high in the tree may succumb to poor weather. Therefore, open-cup nesting birds must balance the threat of predation with challenges from the physical environment during the nest site selection process. Birds may also actively or passively defend their nest. Active nest defense includes nest guarding and direct attacks on predators (Blancher and Robertson 1982, Hatch 1997, Oldendorf and Robinson 2000), whereas passive defense ranges from the concealment of eggs or young by sitting on the nest (Martin 1992, Montgomerie and Weatherhead 1988), to a reduction in parental activity at the nest in response to nest predator activity near the nest (Eggers et al. 2005, Fontaine and Martin 2006, Zanette et al. 2011). Consequently, the interaction between parental behavior and the physical location of the nest can influence nest success. Knowledge of what constitutes a suitable nest site is an important step in understanding the proximate cues that birds use in habitat selection (Wilson and Cooper 1998).

Kingbirds breeding across North America place their nests in orchards, woodland edges, and also in the riparian zone (Murphy 1996a). Kingbirds are an aggressive nest defender (Davis 1941, Blancher and Robertson 1982, Siderius 1993, Redmond et al. 2009) and Murphy et al. (1997) suggested that the use of isolated trees in fields enabled them to detect potential avian predators from a distance. Nests that are placed relatively high in the tree and close to the periphery of the nest canopy provided kingbirds a greater airspace to start aerial attacks (Ricklefs 1977). They often have to balance the risk of predation and weather because nest sites that give the birds greater airspace may lack the 
appropriate cover for nestlings and not be sheltered from weather (Murphy 1983). The trees available to kingbirds breeding at MNWR offer little support for a nest because the branches of willow trees are often vertically oriented. The nest site selection of kingbirds breeding at MNWR has not been studied, however, their preferences for nest sites in other breeding locations has been documented. If kingbirds make adaptive nest site choices, then I would expect (a) that characteristics of the locations of used and unused artificial nests should differ, and (b) that the attributes of artificial nest locations used by kingbirds should closely match those of natural nests. In addition, if nest site selection is adaptive then (c) nest site attributes of successful and failed nests natural should differ.

In summary this thesis examines the possibilities to why kingbirds breeding at MNWR regularly reuse nests, if nest success is dependent on nest placement, and the nest site characteristics. 
CHAPTER 2: EXPERIMENTAL EXAMINATION OF NEST REUSE BY AN OPEN-

\title{
CUP NESTING PASSERINE
}

\begin{abstract}
Reuse of open cup nests is uncommon to rare among passerine birds despite possible savings of time and/or energy that might allow individuals to breed earlier, lay more (and larger) eggs, and produce and recruit more young. Anecdotal observations of the open-cup nesting Eastern Kingbird (Tyrannus tyrannus), at Malheur National Wildlife Refuge (MNWR), OR, USA, showed that $10 \%$ of females reuse old nests, mainly of American Robin (Turdus migratorius). I therefore deployed artificial nests (ARTs) in 2010 and 2011 at MNWR to provide female kingbirds the opportunity to reuse nests to test the time/energy savings (TES) hypothesis' predictions that nest reuse should (1) be more common in years of late breeding, and that females nesting in ARTs should (2) breed earlier, (3) produce more and larger eggs, (4) fledge more young, and (5) reduce the time to lay replacement clutches following failure compared to females using natural nests. Natural nests weighed 3.5 times more than the material brought to line ARTs; thus novel nest building entailed substantial effort. Female kingbirds used ARTs heavily in both years, and contrary to the TES hypothesis, more so in the earlier year. I also rejected every other prediction of the TES hypothesis with one exception: females that laid replacement clutches in ARTs took less time to replace failed initial nests. Given that most of the predictions of the TES hypothesis were rejected, I conclude that the frequent nest reuse by kingbirds at MNWR results from a shortage of quality nest sites.
\end{abstract}




\section{Introduction}

Nests are critical for the reproduction of birds, and much effort is expended to build them because numerous flights are required to find and deliver the specific materials used in their construction (Hansell 2000). Nest building thus takes time, is energetically costly (Withers 1977; Lens et al. 1994; Moreno et al. 2008), and the costs may appear as delayed start to nesting (Cavitt et al. 1999; Hauber 2002; Safran 2006), reduced clutch size (Weeks 1978; Eberhardt 1994 in Walters et al. 2002; but see Conrad \& Robertson 1993), lower seasonal production of young (Hauber 2002; Safran 2006), and possibly even reduced annual adult survival (Gill \& Stutchbury 2005).

Hence, reuse of nests to avoid or at least reduce the costs of construction would seem prudent, especially if a nest that survives between seasons provides information on the structural integrity of a nest site, or, if nests that previously fledged young are also likely to fledge young in the future (e.g., Richmond et al. 2007; Ellison 2008; but see Cavitt et al. 1999; Styrsky 2005). Indeed, nest reuse occurs commonly among raptors, some woodpeckers, and colonial nesting birds (Wimberger 1984; Siegel-Causey and Hunt 1986; Brown and Brown 1996; Safran 2006). Secondary cavity nesting birds also regularly reuse nests presumably because, in part, usable nest sites are limited (Brawn \& Balda 1988; Dobkin et al. 1995; but see Waters \& Noon 1990; reviewed by Newton 1998). In contrast, although nest reuse is known among open-cup nesting passerines (e.g., Mountjoy \& Robertson 1988; Curson et al. 1996; Bergin 1997; Cavitt et al. 1999; Friesen et al. 1999), it is decidedly uncommon, presumably because suitable nest sites are abundant, nests survive infrequently between years, and the possible costs of nest reuse 
are high. Costs may include an increased probability of failure because reused nests (a) are weathered and weak, (b) accumulate ectoparasite in nest material between years that negatively affect offspring growth and survival (Brown \& Brown 1986; Rendell \& Verbeek 1996), or (c) locations are remembered by nest predators such as corvids (Sonerud and \& 1987). Given the rarity of nest reuse among open-cup nesting passerines, the potential costs would seem to trump the potential savings of time and energy that might otherwise permit earlier breeding or the production of more or larger eggs.

The Eastern Kingbird (Tyrannus tyrannus; hereafter kingbird) is a socially monogamous, Nearctic-Neotropic migrant that breeds over much of North America (Murphy 1996a). They build open-cup nests in trees (MacKenzie \& Sealy 1981; Murphy 1983), exhibit high site fidelity (Murphy 1996b), and frequently renest on the same branch in the same nest tree used in previous years (Blancher \& Robertson 1985; Murphy 1996a, 2004). With the exception of Redmond et al. (2007), there are no previous reports of the reuse of con- or heterospecific nests either within or across seasons (Davis 1955 [Montana]; MacKenzie \& Sealy 1981 [Manitoba]; Blancher \& Robertson 1985 [Ontario]; Murphy 1986 [Kansas]; M. T. Murphy [New York, pers. observ.]), although it does occur rarely ( $<1 \%$ of nest attempts in Kansas and New York, M. T. Murphy, unpubl. data; Bergin 1997). The exception is the population of kingbirds breeding at Malheur National Wildlife Refuge (MNWR) in southeastern Oregon, where nest reuse accounts for $~ 10 \%$ of nest starts. Kingbirds at MNWR most commonly refurbish old American Robin (Turdus migratorius; hereafter robin) nests (48.6\% of reused nests; Redmond et al. 2007). 
The high reuse of conspecific nests by kingbirds at MNWR is thus unique for this species, as is the high frequency of heterospecific nest reuse compared to other open-cup nesting passerines (see Styrsky 2005 and Ellison 2008). Kingbirds begin to nest later at MNWR than at all other sites where they have been studied (see studies cited above), probably because of the delayed phenology associated with MNWR's high elevation $(1,256 \mathrm{~m})$. In kingbirds, delayed breeding is associated with smaller clutch size (Murphy 1986), reduced probability of replacing failed initial nesting attempts (Cooper et al. 2011), and at least among male offspring, reduced probability of recruitment (Dolan et al. 2009). The delayed breeding season at MNWR thus possibly favors nest reuse as a means to save time and/or energy so that females can start egg-laying sooner, produce more young, and/or fledge them with a higher probability of recruitment.

On the other hand, nesting habitat for kingbirds at MNWR is restricted almost exclusively to the riparian zone of the Donner und Blitzen River running through the center of the refuge. Elsewhere, kingbirds usually place nests along the distal half of horizontal branches that provide high quality structural support (MacKenzie \& Sealy 1981; Murphy 1983) and air space for parental defense of nests (Murphy et al. 1997; Redmond et al. 2009a). The branching structure and the mainly vertical orientation of the relatively young willow trees comprising $>95 \%$ of the tree species along the river at MNWR (Redmond et al. 2009b) may provide few high quality nest sites, and, favor reuse of the structurally sound mud nests of robins that survived the winter, and which are likely to also survive milder summer conditions. In other words, kingbirds may be making the best of a bad situation. 
In the present paper, I test two competing hypotheses that potentially explain frequent nest reuse by kingbirds. The time/energy savings (TES) hypothesis predicts nest reuse saves time and/or energy, therefore the use of artificial nests (ART) (1) should be more common in years when breeding is delayed, and within years, females using ARTs should (2) breed earlier and invest more in clutches (more and possibly larger eggs), and (3) more rapidly replace failed first nesting attempts than females that build their own replacement nests. As a corollary of prediction (3), (4) frequency of nest reuse should increase as the end of the breeding season approaches. By contrast, the nest site shortage (NSS) hypothesis predicts nest reuse occurs because quality natural nest (hereafter "NAT") sites are limited, therefore (1) ARTs should be used frequently and independently of annual differences in timing of breeding. Furthermore, within years, females using ARTs will not (2) breed earlier or invest more in clutches, or (3) renest sooner than females building NAT replacement nests. Finally, the NSS hypothesis predicts (4) the use of ARTs should be equally likely at all times of the breeding season.

\section{Methods}

Study Site

MNWR is located in southeastern Oregon $\left(42^{\circ} 49^{\prime} \mathrm{N}, 118^{\circ} 54^{\prime} \mathrm{W}\right)$, at the northern end of the Great Basin Desert. Demographic and behavioral research has been conducted on kingbirds at MNWR since 2002. From a demographic perspective, the riparian and wetland habitats of the refuge represent an ecological island for kingbirds surrounded by 
uninhabitable high desert (Redmond and Murphy 2012). MNWR runs north-south for roughly $50 \mathrm{~km}$ and its east-west width varies between 1 and $10 \mathrm{~km}$. The experiments were conducted in 2010 and 2011 at two locations: the main study site located in the southern third of the refuge, and a smaller study site located about $5 \mathrm{~km}$ north of the northern boundary of the main study area (Buena Vista; see map in Redmond and Murphy 2012). The main study area included all sections of the Donner und Blitzen River from Page Springs to a point $2 \mathrm{~km}$ north of the bridge to Krumbo Reservoir, along with a tributary that formed the eastern border of the refuge (East Canal) and a canal that connected East Canal to the main river (Bridge Creek). The Buena Vista study site was also centered on the Donner und Blitzen River. Access to nesting habitat at both sites was provided by the refuge's main gravel road that paralleled the Donner und Blitzen River (Center Patrol Road [CPR]) from a distance of $\leq 5 \mathrm{~m}$ throughout most of its length. Additional roads paralleled East Canal and Bridge Creek at a distance of $\leq 3 \mathrm{~m}$.

\section{General Field Methods}

Complete census of nesting habitat has begun by mid- to late May (depending on weather) since 2002, roughly four weeks before the peak in egg-laying. I checked all suitable habitats to locate nests by searching trees where pairs were repeatedly found, and located $80-85 \%$ of nests before or during egg-laying; nearly all others were found during incubation. Nests were checked at 2 to 3 day intervals, but more frequently near laying and hatching. I documented the dates on which first eggs were laid (= breeding date), clutch size, number of eggs to hatch and young to fledge, and determined incubation period (hatch date of last egg - laying date of last egg). Breeding dates for nests found 
after egg-laying were established by back-dating from known events (e.g., hatching), by aging young using measures of size (Murphy 1981), and assuming a 15 day incubation period (see below). The maximum length $(\mathrm{L} ; \mathrm{cm})$ and breadth $(\mathrm{B} ; \mathrm{cm})$ of eggs were measured using dial calipers (nearest $0.05 \mathrm{~mm}$ ) from nests that were accessible, and for eggs measured prior to incubation, egg mass was measured to the nearest $0.1 \mathrm{~g}$ (Pesola scale). Linear measurements were converted to mass for eggs measured during incubation using the formula mass $=\mathrm{C}\left(\mathrm{Lx} \mathrm{B}^{2}\right)$, where $\mathrm{C}=0.54$ (M. T. Murphy, unpubl. data). Kingbirds raise a single brood year ${ }^{-1}$, but in all years, most pairs replaced failed first nesting attempts by renesting within $150 \mathrm{~m}$ of the initial nests. I collected identical data for replacement nests. Adults were captured by mist net and individually banded using a combination of a numbered metal federal band and three colored plastic bands. Males were captured throughout the breeding season using playback of kingbird song, and both sexes were captured at the nest while they made trips to feed nestlings.

\section{Construction and Deployment of Artificial Nests}

ARTs matched the size, shape, and composition of robin nests because this was the species whose nests kingbirds most commonly reused. I used a $12.5 \mathrm{~cm}$ diameter and $8 \mathrm{~cm}$ deep plastic Rubbermaid ${ }^{\mathrm{TM}}$ food-storage container as a mold into which I pressed $3.2 \mathrm{~cm}$ diameter chicken wire to produce a 6 to $8 \mathrm{~cm}$ deep bowl-shaped frame. Wire frames were spray painted flat brown to eliminate shininess. I pressed a mixture of mud and dried grass into the chicken wire to create a continuous layer of mud that closely approximated the appearance of an old robin nest (Plate 1). ARTs were air dried, and four lengths of string were tied to the wire on the outside so that the structure could be tied to 
branches of trees. The longer $(11.4 \pm 0.14 \mathrm{~cm}[\mathrm{SE}], N=30)$ and shorter $(11.2 \pm 0.13 \mathrm{~cm}$, $N=30$ ) inner diameters of a random sample of ARTs were nearly identical, and depth averaged $6.4 \mathrm{~cm}( \pm 0.15 \mathrm{~cm})$. Kingbird nests are slightly elliptical (outer diameter of nests: $11.9 \mathrm{~cm}$ and $13.3 \mathrm{~cm})$; the inner diameters $(7.4 \mathrm{~cm}$ and $7.9 \mathrm{~cm})$ and depth of $(4.5$ cm; Murphy 1996a) are small enough to fit within the ART's cup.

Spring of 2010 was unseasonably cool and wet, and vegetation phenology was delayed (D. Evered, Malheur Field Station Manager, pers. comm.). Very few kingbirds were seen before 30 May and breeding was delayed (see below). I began at the south end of the river at Buena Vista on 2 and 3 June and deployed the first 30 nests along the river at $100 \mathrm{~m}$ intervals. On 12 and 15 June I deployed an additional 10 nests on each day over the next $2 \mathrm{~km}$ of riparian habitat. Thus, 50 ARTs were spaced evenly over the first $5 \mathrm{~km}$ of the Donner und Blitzen River at Buena Vista in 2010.

On May $10^{\text {th }}$ and $11^{\text {th }}$ of 2011 I deployed 65 ARTs along $6.5 \mathrm{~km}$ of the Donner und Blitzen River at Buena Vista, including the $5 \mathrm{~km}$ used in 2010. I expanded the study to include the main study area by attaching 25 ARTs to trees spaced at $100 \mathrm{~m}$ intervals along the entire length of the canal at Bridge Creek on 13 and 14 May, 2011. I attempted to replicate natural variation in nest placement along the river and canal, and therefore because virtually all riparian NATs overhung water, ARTs were deployed from a canoe.

The Donner und Blitzen River flooded in June 2010, and from mid May through June of 2011, immediately after nests were deployed in both years. The flood of 2011 was particularly severe and it prevented me from checking nests until 22 June, at which time I replaced 20 of 65 ARTs damaged by the flood. Water control structures prevented 
flooding at Bridge Creek, but the refuge administration refused permission to canoe there until 22 June. Given that my access to the river was equally limited for both NATs and ARTs, the constraints imposed by the flooding affected my ability to monitor all nests equally. Once access was possible, I checked nests every second day. As described above, I followed nests throughout the nesting cycle to document contents until nests either failed or fledged young. If a nest failed, I followed the pair to determine if they renested, and if so, whether they used an ART or built a NAT as a replacement. Time taken to replace a failed nest was recorded as date of first egg in the replacement nest minus date of failure of the initial nest.

Used ARTs and NATs were collected in 2010 and 2011 when the nest either failed or fledged young to compare the amount of nest material used to construct each type. I placed nests in plastic Ziploc® bags. In the laboratory, I separated the outer, coarser nest structure from the inner, finer nest lining, and disassembled the two sections separately to remove all non-nesting materials, including dried fecal material, adult and larval insects, other arthropods, and other non-nest material. I placed the remaining materials into paper bags before removing moisture in a drying oven for 24 hours at $36^{\circ} \mathrm{C}$. Upon removal from the oven, I immediately weighed the bag (Ohaus Adventurer AR3130) and its contents to the nearest $0.01 \mathrm{~g}$, reweighed the empty bag, and subtracted the bag's mass from the total to obtain the mass of each nest component. Masses are reported for the inner lining, outer coarser section, and the entire nest.

Statistical Analyses 
I compared average breeding date of initial nest attempts for 2010 and 2011 to the previous eight years using analysis of variance (ANOVA) to evaluate relative timing of breeding in the two years covered by my experiment. To calculate the proportion of females that used ARTs I limited the analysis to females that nested inside or within 200 $m$ of the zone of the river where ARTs were distributed. Given that the distance between kingbird nests is generally $\geq 200 \mathrm{~m}$ (Redmond et al. 2009b), every female within this area should have had at least three ARTs available to her.

Comparisons of the mass of nest materials between NATs and ARTs were made using Student's $t$-test, with correction for unequal variances if necessary. Because the TES hypothesis predicts a decline in the investment in nests as the end of the breeding season approached, I further tested for difference between the mass of the inner and outer lining and total mass of NATs and ARTs using analysis of covariance with breeding date as a covariate.

I used $t$-tests to test the TES hypothesis' prediction that ART use enables females to breed earlier, produce more and/or larger eggs, and fledge more young, by comparing reproductive traits of females using ARTs and NATs. However, because of possible confounding influences of other variables, I also used general linear models (GLM) to control statistically for other variables. For instance, I compared breeding date of first nests of the season with nest type (NAT $=0, \mathrm{ART}=1)$ and year as fixed factors. I also used logistic regression to test the prediction that the use of ARTs would be more common later in the season. I then included all nests (first and replacement) to test the TES hypothesis' prediction that clutch size, egg mass, and/or total clutch mass (= clutch 
size x egg mass) would be larger in ARTs by including nest type, year, and nest attempt (initial $=0$, replacement $=1$ ) as fixed factors, and breeding date as a covariate in a GLM analysis. Breeding date was included because of the regular seasonal decline in reproductive investment that occurs in kingbirds (Blancher and Robertson 1985; Murphy 1986). I further tested for differences in reproductive success between the two nest types by calculating daily survival rate using the logistic Mayfield method (Hazler 2004) based on a 35 day exposure period ( 3 days for egg-laying, 15 days of incubation, and 17 days as nestlings; Murphy 1996a). Finally, to test the TES hypothesis' prediction that the use of ARTs would allow more rapid nest replacement, I used a Student's $t$-test to compare the time taken to replace a nest between females that used NATs or ARTs for replacement nests.

I used STATISTIX (Analytical Software 2009) for all analyses, all tests were two-tailed, and I assumed statistical significance at $P \leq 0.05$. Statistics are reported as mean \pm SE. Means reported in association with GLM are least squares means.

\section{Results}

Mean breeding date of initial clutches over the first eight years of the larger demographic study (2002 to 2009) was 17 June ( \pm 0.40 days, $N=354$ nests). Breeding began later in both 2010 (25.5 June \pm 1.03 days, $N=48$ ) and 2011 (22.5 June \pm 1.14 days, $N=39 ; F_{2,438}=33.91, P<0.001 ;$ Fig. $\left.2-1\right)$. Although both years were late, mean laying date for 2010 was later than that of $2011\left(t_{85}=2.69, P=0.009\right)$. Indeed, $82.1 \%$ of 
females began to lay before 25 June in 2011 , but only $43.8 \%$ began by that date in 2010 . Median laying date over the first eight years was 17 June, only four days earlier than the median for 2011 (21 June), but 10 days earlier than in 2010 (27 June). Median laying date was significantly earlier in 2011 than in $2010\left(X^{2}=17.25, P<0.001\right.$; Fig. $\left.2-1\right)$.

Most females used an ART if one was available. At Buena Vista, 61.1\% (11 of 18) and $93.8 \%$ (15 of 16) of female kingbirds built in ARTs in 2010 and 2011, respectively. The use of ARTs by nearly every female in 2011 for their initial nest resulted in a significantly higher use of ARTs in 2011 (the earlier year) than in 2010 (Fisher's Exact Test, $P=0.042$ ), a result opposite of that predicted by the TES hypothesis. The frequency of ART use at Bridge Creek in 2011 (71.4\% [5 of 7 females]) did not differ from that at Buena Vista in either 2010 (Fisher's Exact Test, $P=0.502$ ) or 2011 (Fisher's Exact Test, $P=0.210$ ). Of females with access to ARTs, the probability that one would be used was lower later than early in the season (logistic regression, $\beta=-$ $0.110 \pm 0.043, P=0.010$ ), a result again opposite of that predicted by the TES hypothesis.

Nest Mass and Incubation Period

The mass of the lining of ARTs $(10.7 \pm 1.03 \mathrm{~g}, N=28)$ and NATs $(13.2 \pm 1.55 \mathrm{~g}$, $N=19)$ did not differ $\left(t_{45}=1.40, P=0.168\right)$. Breeding date was not known for all of the collected nests, but after accounting for variation associated with breeding date for those with a known date, the lining of ARTs $(9.7 \pm 1.39 \mathrm{~g}, N=18)$ weighed less than those of NATs $\left(13.8 \pm 1.39, N=18 ; F_{1,33}=4.15, P=0.050\right)$. ARTs had virtually no outer layer $(1.4 \pm 0.56 \mathrm{~g}, N=28)$ compared to NATs $\left(28.2 \pm 3.76 \mathrm{~g}, N=18 ; t_{45}=7.04, P<0.001\right)$. 
Consequently, the total mass of ARTs $(12.1 \pm 1.02 \mathrm{~g})$ was only $29.2 \%$ of NATs $(41.4 \pm$ $4.06 \mathrm{~g} ; t_{45}=6.83, P<0.001 ;$ Fig. $\left.2-2\right)$. The lower investment in nest materials by females using ARTs did not appear to result in a poorly insulated nest because incubation period for eggs in ARTs and NATs did not differ. Analysis of covariance of incubation period with year and nest type as factors and breeding date as a covariate showed that incubation period did not vary with date $\left(F_{1,38}=0.95, P=0.336\right)$, was longer in $2010(15.4 \pm 0.19$ days, $N=21)$ than $2011\left(14.9 \pm 0.15\right.$ days, $\left.N=21 ; F_{1,38}=4.40, P=0.043\right)$, but did not differ between ARTs $(15.2 \pm 0.23$ days, $N=9)$ and NATs $\left(15.1 \pm 011\right.$ days, $N=33 ; F_{1,38}$ $=0.15, P=0.705)$.

\section{Nest Type and Reproduction}

Univariate comparisons (Table 2-1) suggested that first clutches were laid marginally earlier in ARTs than NATs, but after accounting for annual differences in breeding date (Table 2-2), egg-laying began at roughly equal times for females that used ARTs (23 June \pm 1.03 days, $N=28$ ) and NATs (24.5 June \pm 0.72 days, $N=59$ ). Univariate comparisons (Table 2-1) and GLM analysis (Table 2-2) failed to find any differences between the two nest types for the remaining variables. For instance, clutch size declined with breeding date $(\beta=-0.059 \pm 0.010)$, and after effect of date was accounted for, clutch size was larger in replacement $(3.90 \pm 0.16, N=22)$ than initial (3.30 $\pm 0.08, N=75)$ nests, and was marginally larger in 2011 (Table 2-1). Clutch size of ARTs $(3.55 \pm 0.11, N=29)$ and NATs $(3.65 \pm 0.09$ eggs, $N=68)$ did not differ after accounting for effects of the other variables. Likewise, egg mass of ARTs $(4.20 \pm 0.124$, $N=22)$ and NATs $(4.20 \pm 0.099, N=35)$ were identical after I accounted for marginal 
effects of year and clutch size (Table 2-1). Clutch mass was greater in replacement (18.56 $\pm 0.97, N=8)$ than initial $(15.95 \pm 0.35, N=47)$ nests, declined seasonally $(\beta=-0.195 \pm$ 0.067), but did not differ between NATs $(17.55 \pm 0.590 \mathrm{~g}, N=33)$ and ARTs $(16.98 \pm$ $0.558 \mathrm{~g}, N=22$ ). Brood size differed between years and with clutch size (Table 2-2), but not between ARTs $(3.21 \pm 0.26$ young, $N=18)$ and NATs $(3.09 \pm 0.20$ young, $N=50)$ when the potential effects of the former variables were removed statistically. And finally, for nests that survived to the nestling period, ARTs $(2.02 \pm 0.40$ young, $N=18)$ and NATs $(1.57 \pm 0.28$ young, $N=51)$ fledged similar numbers of young once I accounted for the significant effect of brood size (Table 2-2).

Nest Success and Time to Replace Failed Nests

Fewer nests fledged young in $2010(27.6 \%, 95 \%$ confidence interval $[\mathrm{CI}]=$ $17.7 \%$ to $38.4 \%)$ than in $2011(52.7 \%, 95 \% \mathrm{CI}=36.8$ to $66.2 \%$; logistic Mayfield estimate [Hazler 2004]). I therefore compared percent success of ARTs and NATs separately for the two years. In both years, ARTs and NATs were equally likely to fledge young (mean [95\% CI]; ARTs 2010: 21.0\% [5.2\% to 43.3\%]; NATs 2010: $29.4 \%$ [18.0\% to 41.7\%]; ARTs 2011: $53.8 \%$ [28.1\% to $73.8 \%$ ]; NATs $2011: 51.9 \%$ [31.6\% to $68.8 \%$ ]).

The $6.5 \pm 0.76$ days $(N=7)$ taken to lay the first egg of the replacement nest by females that used ARTs was suggestively shorter than the $8.3 \pm 0.59$ days $(N=14)$ required to replace nests by females that built NAT replacement nests $\left(t_{19}=1.84, P=\right.$ 0.082). Two females built complete replacement NAT nests, but never laid eggs. If I assigned to them the maximum time taken by any female to replace a failed first attempt (13 days), then the resulting $8.9 \pm 0.65$ days $(N=16)$ taken to replace nests by females 
using NATs was significantly longer than for females that used ARTs $\left(t_{21}=2.17, P=\right.$ 0.042; Fig. 2-3). This conclusion held even if time to replacement for the two nests that never received eggs was assumed to be as short as 9 days $\left(t_{21}=2.05, P=0.053\right)$.

\section{Discussion}

Ample experimental evidence indicates that the initiation of egg-laying in birds is often limited by the availability of energy and/or nutrients in the early breeding season (Davies \& Lundberg 1985; Kelly \& van Horn 1997; Schoech \& Hahn 2008). Species breeding at higher latitudes (Sandercock et al. 1999; Gaston et al. 2005) or elevations (Martin \& Wiebe 2004; Bears et al. 2009; Pereyra 2011), face additional constraints imposed by a brief nesting period. Thus, birds, especially those with short breeding seasons, should attempt to reduce energy demands to facilitate the onset of egg-laying. Nest reuse is one potential means of hastening clutch initiation, but its rarity among opencup nesting passerine species suggests that either the opportunity to reuse nests rarely exists, or that the costs of doing so are prohibitive.

The high-elevation MNWR kingbird population breeds later and reuses nests more often than other kingbird populations that have been studied (Redmond et al. 2007). My data also suggest that nest construction is demanding because the mass of NATs built by kingbirds was over three-fold greater than the material used to finish ARTs. I doubt this translates into a three-fold greater investment of energy or time in building NATs because this would assume that the inner lining and outer shell of the nest require equal 
effort to build, which seems unlikely because kingbirds appear most selective of the materials used for the inner lining (Murphy 1996a). Although more work is needed to quantify the time and energy needed to build nests, examples from other species suggest energy investment in nest building is not trivial. Putnam (1949), for instance, showed Cedar Waxwings (Bombycilla cedrorum), delivered food to young at one third- to one quarter the rate at which they brought nest material to build nests. Given the time required to build nests and raise young (5 to 6 days versus 15 to 16 days, respectively; Putnam 1949), Cedar Waxwings made at least as many flights to build nests as to feed young. Withers' (1977) calculations showed the daily energy expenditure of Cliff Swallows, (Petrochelidon pyrrhonota), during nest construction exceeded energy use during both incubation and the nestling period (see also Gauthier \& Thomas 1993; Brown \& Brown 1996). Nest building thus demands substantial effort, and the use of ARTs by kingbirds must have saved time and energy.

Nonetheless, my results suggest kingbirds did not reallocate the saved resources to other aspects of reproduction. Whether basing comparisons on simple means (Table 21), or controlling statistically for potential confounding factors (Table 2-2), females lining ARTs failed to exhibit any difference in timing of breeding, clutch size, egg mass, total clutch mass, incubation period, number of eggs to hatch, or number of young to fledge from females that built NATs. Nest success, while different between years, did not differ between ARTs and NATs in either year. The prediction that females using ARTs would take less time to replace a failed nest was the only prediction of the TES hypothesis that was not unequivocally rejected, but this depended on the assumption that 
two natural replacement nests in which females never laid would have taken at least 9 days to lay replacement clutches if females had laid eggs.

In contradiction to predictions of the TES hypothesis, most females in both years used ARTs, and more importantly, significantly more kingbirds used ARTs in 2011, the earlier year. The nearly universal use of ARTs for initial nests (15 of 16 females) at Buena Vista in 2011 was striking. Prior experience by some of the females with ARTs in 2010 may have contributed to the high use in 2011. However, the very low nest success in 2010 might be expected to reduce the probability of similar nesting behavior in the following year, as prior nest success in kingbirds influences future nesting decisions (Murphy 1996b; Redmond et al. 2009b). A more likely explanation for the nearly universal use of ARTs in 2011 is the unusual weather conditions of that year. The 2011 flood was the most severe of the 10 years kingbirds were studied at MNWR (M. T. Murphy, unpubl. data), and 2011 was the only year that I was denied access to canoe the river (mid-May until late June). Kingbirds commonly nest in low branches overhanging the river that were submerged for most of the prelaying period of 2011, and the loss of $31 \%$ of the initial ARTs deployed in 2011 to flooding attests to the severity of the event. I thus attribute the nearly universal use of ARTs for initial nests in 2011 to an exacerbated shortage of suitable sites, and view this and the frequent use of ARTs in both years as inconsistent with the TES hypothesis, but consistent with the NSS hypothesis.

Over the 10 years of the larger study, most NATs were placed in willow trees $(85.3 \%, N=618)$ that often seem to provide poor support for nests. Elsewhere, kingbirds typically nest well above ground in a diversity of tree species, but all with well supported 
horizontal limbs (see MacKenzie \& Sealy 1981; Murphy 1983; Blancher \& Robertson 1985; Murphy et al. 1997). Box elder (Acer negundo) is the only tree species other than willow to occur fairly commonly along the riparian zones of my study sites at MNWR, but in fact, kingbirds more often nested in low-growing rose (Rosa spp), currant (Ribes spp.), or sage (Artemesia spp.) bushes (total $=7.8 \%)$ than box elders $(1.9 \% ; N=618)$. I frequently found it difficult to find nest sites with appropriately spaced branches to support ARTs in willows, which is consistent with my assumption that they offer inferior nest sites compared to tree species used elsewhere. The use of the ARTs by other bird species, including Mourning Doves (Zenaida macroura), Barn Swallows (Hirundo rustica) (see also Redmond \& Murphy 2007), and robins, further supports the proposal that suitable nest sites are in short supply at MNWR.

In summary, other studies found that nest reuse may be associated with early nesting (Cavitt et al. 1999; Hauber 2002) or high nesting success (Friessen et al. 1999; Wysocki 2004; Ellison 2008; but see Bergin 1997). However, the anecdotal nature of these observations provide limited insight as to the reasons, proximate or ultimate, for this behavior. The experimental framework enabled me to test factors potentially responsible for nest reuse in an open-cup nesting passerine, and allowed me to reject an energy/time saving mechanism in favor of nest site limitation, as suggested by Wysocki (2004) for Blackbirds (Turdus merula). 
Table 2.1. Summary statistics and univariate comparison of reproductive traits of initial nests of the season produced by female eastern kingbirds that either lined an artificial nest or constructed a natural nest at Malheur National Wildlife Refuge, OR, in 2010 and 2011.

\begin{tabular}{lccc} 
& \multicolumn{2}{c}{ Nest type } & \\
& $\bar{x}(\mathrm{SE} ; N)$ & $\overline{\mathrm{x}}(\mathrm{SE} ; N)$ & $t(P)$ \\
Trait & 22.6 June $(1.14 ; 28)$ & 24.8 June $(0.68 ; 60)$ & $1.75(0.084)$ \\
\hline Breeding date & $3.56(0.123 ; 23)$ & $3.50(0.094 ; 54)$ & $0.39(0.695)$ \\
Clutch size & $4.40(0.092 ; 18)$ & $4.27(0.070 ; 31)$ & $1.06(0.294)$ \\
Egg mass $(\mathrm{g})$ & $16.30(0.477 ; 18)$ & $16.36(0.426,31)$ & $0.08(0.933)$ \\
Clutch mass $(\mathrm{g})$ & $15.0(0.22 ; 7)$ & $15.2(0.14 ; 27)$ & $0.62(0.542)$ \\
Incubation period (days) & $1.7(0.34 ; 29)$ & $1.9(0.21 ; 63)$ & $0.52(0.607)$ \\
Number to hatch & $1.4(0.32 ; 30)$ & $1.2(0.19 ; 68)$ & $0.62(0.538)$ \\
\hline
\end{tabular}


Table 2.2. Results of general linear models (GLM) analysis of reproductive traits of eastern kingbirds breeding at Malheur National Wildlife Refuge, OR, in 2010 and 2011. The main comparison, that between females that used artificial or natural nests ("Nest type"), was made after controlling statistically for other potentially confounding variables using GLM analyses.

\begin{tabular}{|c|c|c|c|}
\hline Trait & Predictors & $\mathrm{df}$ & $F(P)$ \\
\hline \multirow[t]{2}{*}{ Breeding date } & Year & 1,85 & $5.11(0.026)$ \\
\hline & Nest type & 1,85 & $1.28(0.261)$ \\
\hline \multirow[t]{4}{*}{ Clutch size } & Year & 1,92 & $3.24(0.075)$ \\
\hline & $1^{\text {st }}$ or replacement & 1,92 & $9.46(0.003)$ \\
\hline & Breeding date & 1,92 & $32.87(0.000)$ \\
\hline & Nest type & 1,92 & $0.65(0.421)$ \\
\hline \multirow[t]{3}{*}{ Egg mass (g) } & Year & 1,52 & $3.05(0.087)$ \\
\hline & Clutch size & 2,52 & $2.23(0.105)$ \\
\hline & Nest type & 1,52 & $0.01(0.988)$ \\
\hline \multirow[t]{3}{*}{ Clutch mass (g) } & $1^{\text {st }}$ or replacement & 1,51 & $5.70(0.021)$ \\
\hline & Breeding date & 1,51 & $7.57(0.005)$ \\
\hline & Nest type & 1,51 & $0.84(0.363)$ \\
\hline \multirow[t]{3}{*}{ Brood size } & Year & 1,60 & $4.51(0.038)$ \\
\hline & Clutch size & 3,60 & $6.60(0.001)$ \\
\hline & Nest type & 1,60 & $0.12(0.734)$ \\
\hline \multirow[t]{2}{*}{ Number fledge } & Brood size & 3,64 & $11.19(0.000)$ \\
\hline & Nest type & 1,64 & $1.48(0.228)$ \\
\hline
\end{tabular}

Year, breeding date, and first or replacement nest (" 1 st or replacement") were included in all models as potential predictors of variation, but were only retained if they were significant or nearly so $(P \leq 0.10)$. Other variables were included in other models when appropriate. For instance, clutch size was included in the analysis of egg mass because of possible association between number and size of eggs, and clutch size and brood size were included in analyses of brood size and number of young to fledge, respectively, because of expected positive relationships between the pairs of variables. 
Figure 2.1. Box-and-whisker plot describing variation in laying date of initial nests of the season for Eastern Kingbirds breeding at Malheur National Wildlife Refuge, OR. Data for the composite sample from 2002 through 2009 are compared to breeding dates in 2010 and 2011. Dates are counted continuously such that $1=1 \mathrm{May}, 32=1 \mathrm{June}$, and $62=1$ July. Horizontal lines represent medians, boxes enclose the middle $50 \%$ of observations, vertical lines represent the $10^{\text {th }}$ and $90^{\text {th }}$ percentiles, and dots are observations outside the latter limits.

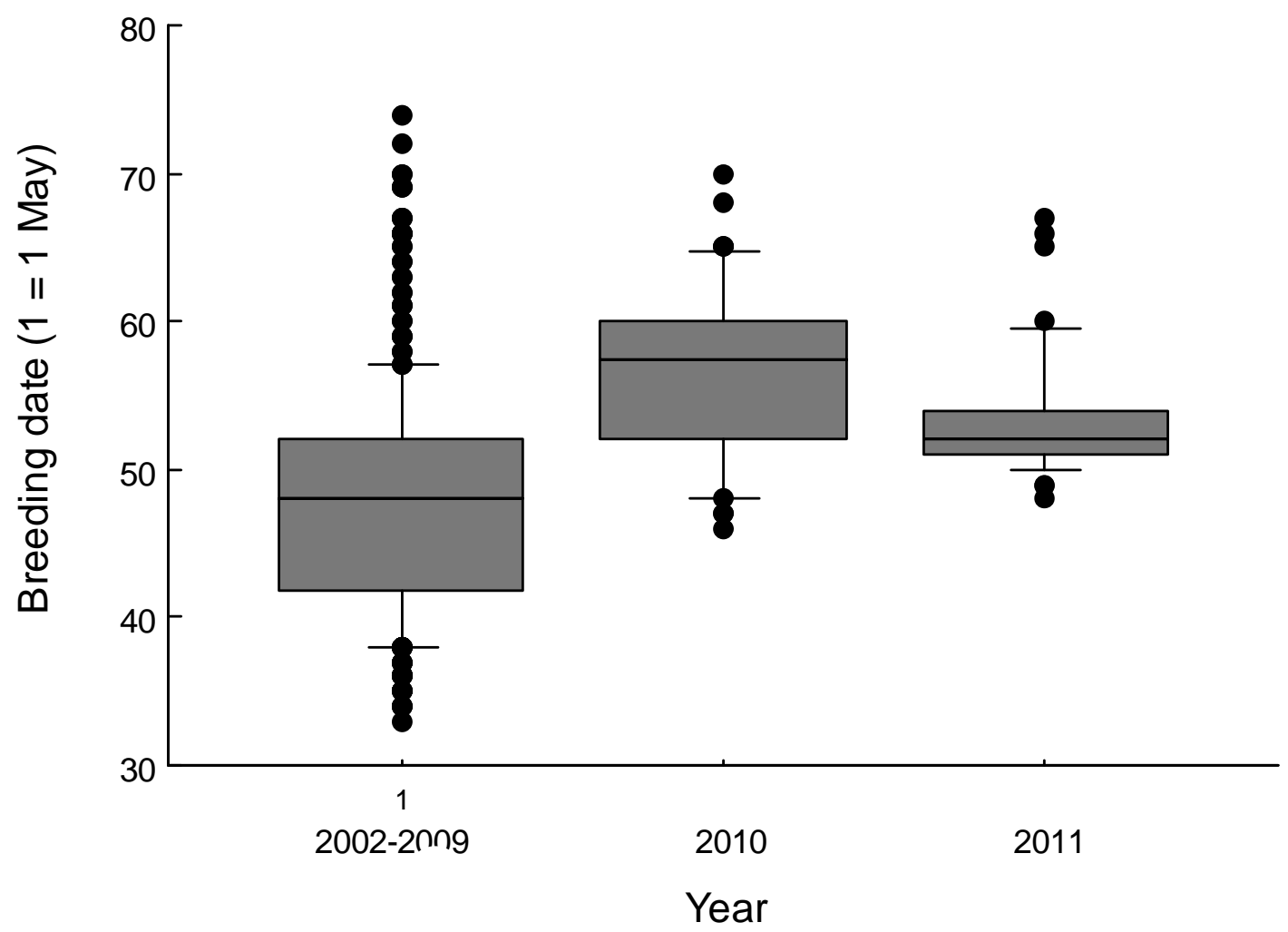


Figure 2.2. Box-and-whisker plot of the mass of artificial and natural nests that the female Eastern Kingbirds constructed in 2010 and 2011 at Malheur National Wildlife Refuge. Horizontal lines represent medians, boxes enclose the middle $50 \%$ of observations, vertical lines represent the $10^{\text {th }}$ and $90^{\text {th }}$ percentiles, and dots are observations outside the latter limits.

\section{Mass of natural and artificial nests}

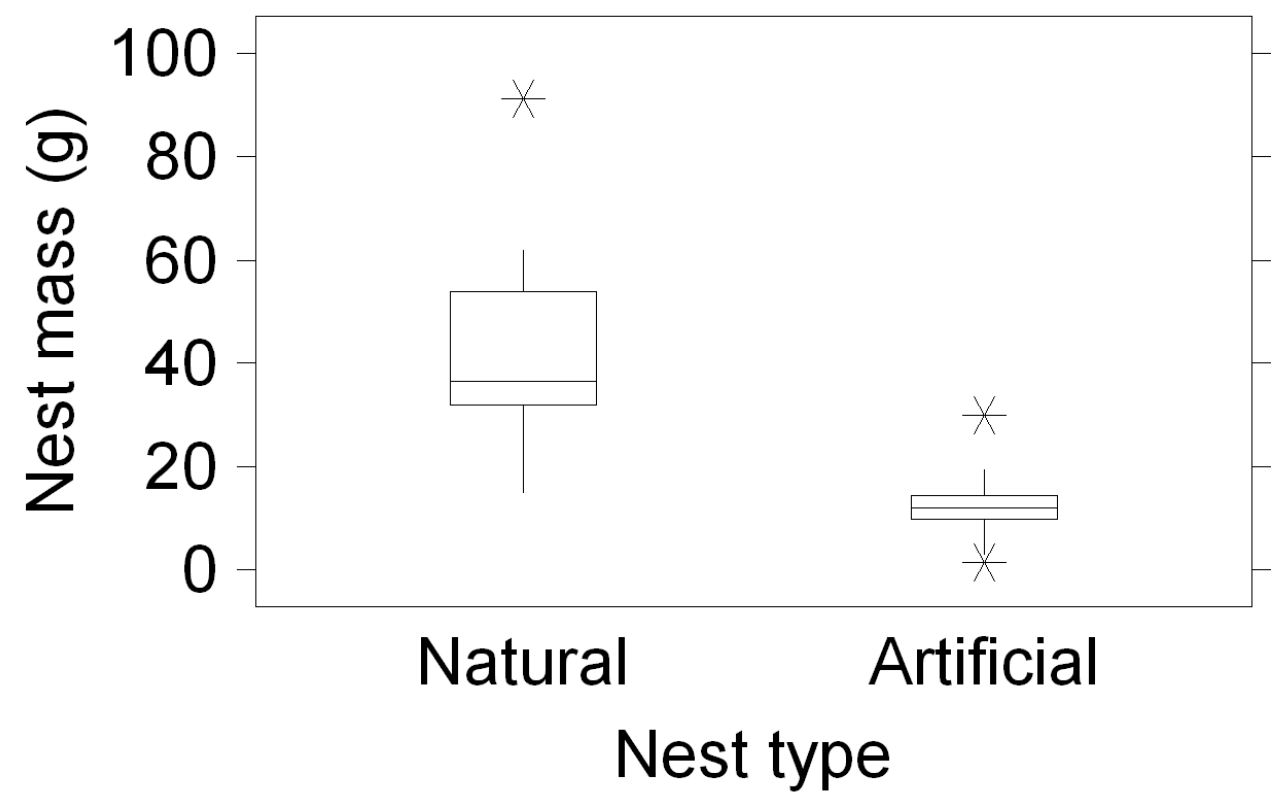


Figure 2.3. Box-and-whisker plots of the time taken to replace failed nests by female Eastern Kingbirds that subsequently laid eggs in either an artificial nest or built a natural nest at Malheur National Wildlife Refuge in 2010 and 2011. Horizontal lines represent medians, boxes enclose the middle $50 \%$ of observations, vertical lines represent the $10^{\text {th }}$ and $90^{\text {th }}$ percentiles, and dots are observations outside the latter limits.

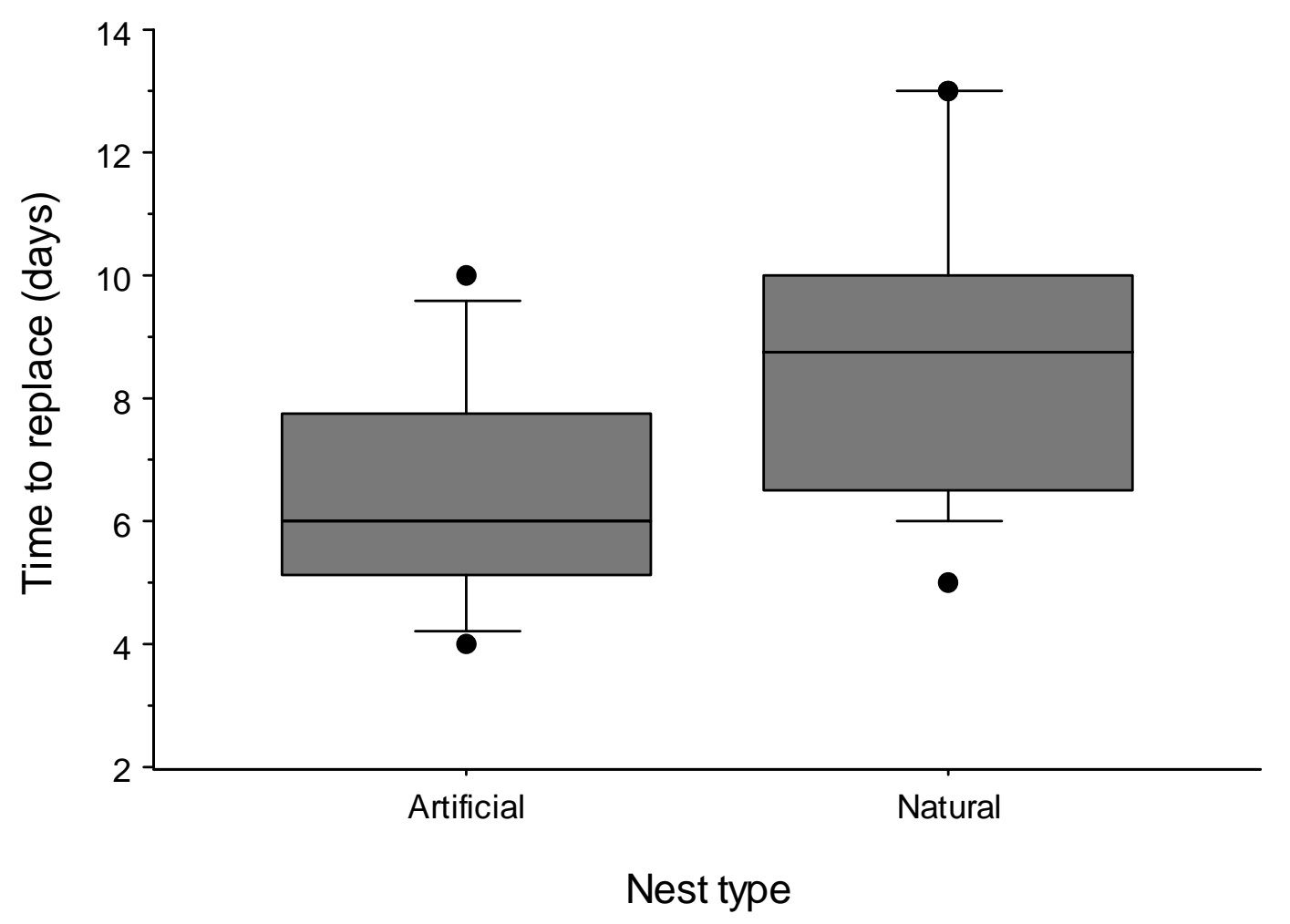


Figure 2.4. View of two artificial nests attached to willow limbs at Malheur National Wildlife Refuge. Image on left depicts a fairly typical nest placement with mud and grass lining visible inside wire frame. Image on the right is a top down view of a lined artificial nest with a nestling and two unhatched eggs (and an old willow catkin).

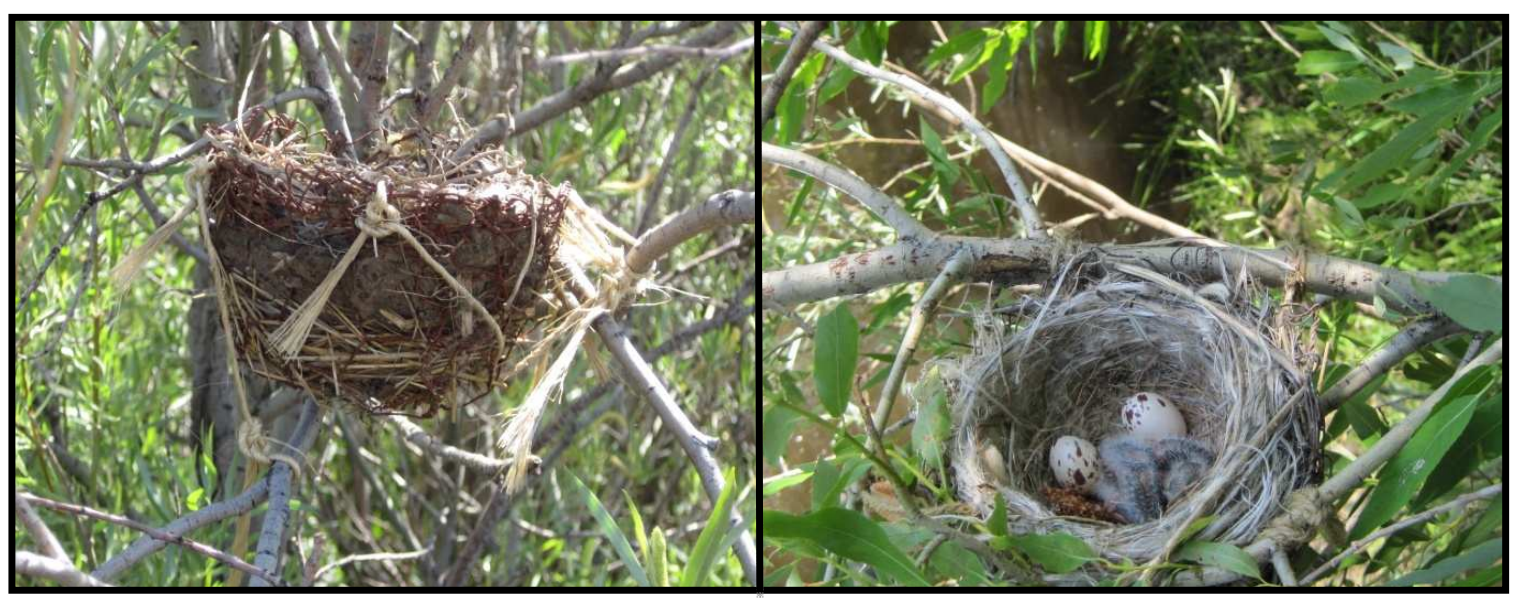




\title{
CHAPTER 3: NEST SITE SELECTION IN EASTERN KINGBIRDS
}

\begin{abstract}
Nest predation has been identified as the most important cause of nest failure in passerine birds. The nest site characteristics that birds choose are presumably under selection because the nest site will ultimately affect the probability of nest detection by predators, and how many young are fledged. Eastern Kingbirds (Tyrannus tyrannus) breeding at Malheur National Wildlife Refuge (MNWR) face high rates of nest failure because of nest predation by corvids. Eastern Kingbirds should therefore choose nest site locations that limit the chance of predation. I used artificial nests (ARTs) placed in trees in habitats used by kingbirds to investigate nest site selection. I took vegetation measurements on nest site variables on all natural nests, used ARTs, and unused ARTs (located within $200 \mathrm{~m}$ of an Eastern Kingbird pair). Principal component analysis was used for nests that were located on or near the river to produce a multivariate description of nest position for two categories (natural and artificial nests), and to compare failed and successful nests. I found a consistent pattern in placement of successful natural and successful artificial nests to be placed higher in the tree and on more vertically oriented limbs than failed nests. Probability of nest success (i.e., fledged $\geq 1$ nestling) increased as nests become more vertically oriented, and among successful nests, more young fledged from nests with high cover around the nest. These results suggest that nest site use by Eastern Kingbirds represents active selection by females, and the preferred traits are associated with a higher probability of success.
\end{abstract}




\section{Introduction}

Nest failure generally accounts for over $50 \%$ of nesting attempts among open-cup nesting passerine birds (e.g., Filliater et al. 1994, Murphy 2000), and nest predation is virtually always the leading cause of nest failure (Ricklefs 1969, Martin and Li 1992, Martin 1993). Eggs and nestlings of altricial species remain exposed to nest predators for generally no less than three to four weeks, and consequently, selection of safe nest sites is viewed as a critical behavior contributing to reproductive success and fitness (Forstmeier and Weiss 2004, Latif et al. 2012). This should be especially true for short-lived birds that may have few opportunities to breed over their brief lives; individuals that make poor choices are presumably eliminated rapidly from the gene pool, and thus, nest sites should reflect strong selection for secure sites. Probability of nest success will also be affected by the parents' ability to defend the nest against predators, and thus species-specific patterns of nest choice are presumably a product of the interplay between attempts to limit the predators access to nests, and potentially, facilitate parental defense of the nest.

Nest concealment is probably the first line of defense against predators, and a host of studies have shown that well concealed nests built in dense vegetation have a reduced risk of nest predation (Colias and Colias 1984, Götmark 1995; but see Howlett and Stutchbury 1996, Holway 1991). Well concealed nests are probably most likely to escape detection by active, visually searching predators (Santisteban et al. 2002, Weidinger 2002), and birds have been shown to respond to high perceived risk of nest predation by preferentially locating nests in dense cover (Zanette et al. 2011). Placing nests in trees well above ground is probably a direct defense against primarily ground and low shrub 
foraging predators such as many mammals and reptiles, and indeed, a number of studies have found placement of nests higher in shrubs or trees to be effective at reducing nest losses (Murphy 1983, Wilson and Cooper 1998, Burhans et al. 2002). Locating nests towards the end of branches may further reduce threats from arboreal predator species such as sciurids and snakes, but nests placed high in trees and near the edge of the canopy are more exposed to severe weather (i.e., high winds, rain), intense sunlight, and avian nest predators. Nesting birds must thus balance threats from different nest predators and the physical environment during the nest site selection process. Flexibility in choice of nest sites would seem adaptive, and indeed, evidence exists to suggest that individuals can over time modify nest placement in a manner to increase the probability of nest success (Marzluff 1988, Forstmeier and Weiss 2004, Latiff et al. 2012).

In addition to nest placement, birds may use a range of behaviors to actively or passively defend their nest. Active nest defense includes nest guarding and direct attacks on predators (Blancher and Robertson 1982, Hatch 1997, Oldendorf and Robinson 2000), whereas passive defense ranges from the concealment of eggs or young by sitting on the nest (Martin 1992, Montgomerie and Weatherhead 1988) to reduction in parental activity at the nest in response to nest predator activity near the nest (Eggers et al. 2005, Fontaine and Martin 2006, Zanette et al. 2011). Ultimately, it is the interplay between parental behavior and the physical location of nests that have the potential to influence probability of nest success, and knowledge of what constitutes a suitable nest site is an important step in understanding the proximate cues that bird use in habitat selection (Wilson and Cooper 1998). 
The Eastern Kingbird (Tyrannus tyrannus; hereafter kingbirds) is a NearcticNeotropical migrant that breeds in North America from coast to coast. Breeding habitat includes open, savanna-like environments ranging from fields with scattered trees and shrubs, to orchards and woodland edges, but they also regularly nest in riparian habitat and on the margins of lakes and ponds (Murphy 1996a). Kingbirds are socially monogamous, exhibit high site fidelity (Murphy 1996b), and the often conspicuous opencup nests is built in trees by females without male assistance (Davis, 1941, MacKenzie and Sealy 1982, Murphy et al. 1997, Murphy 1996a). Kingbirds have a relatively long nest cycle (Murphy 1983), which increases the potential for detection by nest predators. Not surprisingly, over 50\% of nests fail in most years (Murphy 2000), and avian predators are the leading cause of nest failure (Murphy 1996b). Kingbirds are well known for their aggressive attacks on potential nest predators (Davis 1941, Blancher and Robertson 1982, Siderius 1993, Redmond et al. 2009), and Murphy et al. (1997) argued that the use of isolated trees in fields enabled kingbirds to detect potential avian predators from a distance, and that placement of nests relatively high in the tree and close to the edge of the canopy provided open-air space to initiate aerial attacks (see also Ricklefs 1977).

I studied the nest site selection by Eastern Kingbirds at Malheur National Wildlife Refuge (MNWR) in the summer of 2010 and 2011 to evaluate whether success was contingent on nest placement. Previous studies of the nesting kingbirds in Manitoba (MacKenzie and Sealy 1982), Kansas (Murphy 1983), New York (Murphy 1983, Murphy et al. 1997), and Ontario (Blancher and Robertson 1985) showed that kingbirds regularly 
nest near the edge of the canopy at a height aboveground ( 6 to $7 \mathrm{~m}$ ) that approximated $60-70 \%$ of tree height. MNWR presents a very different environment from previous sites where kingbirds have been studied because nesting is almost entirely restricted to riparian zones where the dominant trees are young willows (Salix spp.). Willows appear to be relatively poor nest sites for kingbirds (Redmond et al. 2007, Chapter 2), and the apparent shortage of high quality nest sites is presumably the reason why $\sim 10 \%$ of kingbird nests at MNWR are built in old nests of mainly other species (Redmond et al. 2007). Kingbirds at MNWR regularly build nests in artificial nests placed in trees (Chapter 2) and I used this unusual behavior to ask whether kingbird nest site selection at MNWR is adaptive (i.e., results in higher reproductive success). To do this, I distributed artificial nests at a range of locations in trees in habitat used typically by kingbirds and compared locations of natural nests and artificial nests with my hypothesis being that if nest site selection is not random, then (1) attributes of the locations of used and unused artificial nests should differ, and (2) the attributes of artificial nest locations used by kingbirds should approximate those of natural nests. In addition, if nest site selection is adaptive then (3) nest site attributes of successful and failed nests natural should differ, and that successful and failed artificial nests should mirror this difference such that successful natural and artificial nests closely resemble each other.

\section{Methods}

Study site 
MNWR is located in southeastern Oregon at the northern end of the Great Basin desert $\left(42^{\circ} 49^{\prime} \mathrm{N}, 118^{\circ} 54^{\prime} \mathrm{W}\right)$. Demographic and behavioral research on the MNWR kingbird population has been conducted continuously since 2002 . The riparian and wetland habitats used by kingbirds at MNWR are embedded in an unusable desert landscape, and as a consequence, MNWR is an ecological island for kingbirds (Redmond and Murphy in 2012). The refuge is $\sim 60 \mathrm{~km}$ long and 3-10 km wide. My experimental research was conducted in 2010 and 2011 mainly near Buena Vista, an area located $5 \mathrm{~km}$ north of the long-term primary research site located in the lower third of the refuge. In 2011 I also conducted additional experiments at a site (Bridge Creek) within the longterm primary research area (see map in Redmond and Murphy 2012). The long-term primary research area included all sections of the Donner und Blitzen River from Page Springs to a point $2 \mathrm{~km}$ north of the bridge to Krumbo Reservoir, along with East Canal (the tributary that forms the eastern border of the refuge) and Bridge Creek. The refuge's main gravel road (Center Patrol Road [CPR]) paralleled the Donner und Blitzen River from a distance of $\leq 5 \mathrm{~m}$ and provided access to nesting habitat at the primary research site and Buena Vista. Roads also paralleled East Canal and Bridge Creek at a distance of $\leq 3 \mathrm{~m}$.

\section{Field methods}

I followed methods used in previous years to conduct complete census of nesting habitat, and document seasonal reproductive success for every known kingbird pair that nested within the two study areas. I located the kingbird's conspicuous nests by searching the trees by both land and water (in canoe) located where pairs were repeatedly found; 
$80-85 \%$ of nests were found before or during egg-laying. Nests were checked every other day, and I documented dates on which first eggs were laid (i.e., breeding date), clutch size, and hatching and fledging success (i.e., number of eggs to hatch and young to fledge, respectively). Breeding dates for nests found after egg-laying were determined by back-dating from known events (e.g., hatching), by aging young using measures of size (Murphy 1981), and assuming a $15 \mathrm{~d}$ incubation period (Chapter 2). Kingbirds raise one brood year $^{-1}$, but nest failure is common. Failed initial nests are usually replaced by a renest within $\sim 150 \mathrm{~m}$ of the initial nests, and I collected identical data from these nests. Kingbird nestlings usually fledge 16-17 days after hatching, and to verify nest success, I searched for fledglings in trees near the nest because fledglings usually remain in or close to the nest tree for the first few days out of the nest (Murphy 2000).

\section{Artificial nests: Construction and deployment}

Kingbirds regularly reuse nests of American Robins (Turdus migratorius; hereafter robin) at MNWR (Redmond et al. 2007). Hence, artificial nests (hereafter ARTs) were constructed to resemble robin nests in size, shape, and composition. I used a $12.5 \mathrm{~cm}$ diameter and $8 \mathrm{~cm}$ deep plastic Rubbermaid food-storage container as a mold to form a wire frame by pressing $3.2 \mathrm{~cm}$ diameter "chicken wire" into the mold. Frames (6 to $8 \mathrm{~cm}$ deep) were spray painted flat brown to eliminate shininess. I then formed a solid interior by pressing dried grass and a layer of mud into the wire frame. I air dried the ARTs and tied four lengths of twine to the frame so that they could be tied to branches of trees. The inner diameters and depth $(7.4 \mathrm{~cm}, 7.9 \mathrm{~cm}$, and $4.5 \mathrm{~cm}$, respectively; Murphy 
1996a) of natural kingbird nests (hereafter NAT) fit easily within an ART's interior (inner diameter $=11.3 \mathrm{~cm}, \mathrm{n}=30$ ), and were readily used by kingbirds (Chapter 2).

Kingbirds normally arrive at MNWR by mid-May, but in 2010 I saw very few before 30 May because of unseasonably cool and wet weather. On June $2^{\text {nd }}$ and $3^{\text {rd }} I$ deployed 30 ARTs in trees at $100 \mathrm{~m}$ intervals at the south end of the river at Buena Vista near the Diamond Lane bridge. I moved northward through an area regularly used by kingbirds (M. T. Murphy, pers. comm.). I deployed 10 more ARTs on both 12 and 15 June through the next $2 \mathrm{~km}$ of riparian habitat so that a total of 50 ARTs were spaced evenly over the first $5 \mathrm{~km}$ of the Donner und Blitzen River at Buena Vista.

In 2011 I deployed 65 ARTs at $100 \mathrm{~m}$ intervals along $6.5 \mathrm{~km}$ of the Donner und Blitzen River at Buena Vista on 10 and 11 May. This included the $5 \mathrm{~km}$ used in 2010 plus the next $1.5 \mathrm{~km}$ of river. I also added 25 ARTs to Bridge Creek of the main study area on 13 and 14 May to bolster sample size. ARTs were again spaced at $100 \mathrm{~m}$ intervals. All ARTs (2011: $\mathrm{n}=50 ; 2012, \mathrm{n}=90)$ were deployed from a canoe, and overhung water at heights constrained by the need to stand and reach upward to tie nests to branches from a canoe in moving water. To expand the range of sites supporting ARTs, I added 6 and 4 nests, respectively, at Buena Vista and Bridge Creek to branches near the tops of trees that overhung land but were $\leq 5 \mathrm{~m}$ from the river.

The Donner und Blitzen River flooded in June of both years, but in 2011 it rose to such an extent that, after deployment of ARTs, MNWR management refused permission to canoe the river until 22 June. Damage or loss of ARTs because of submersion during the flood in 2011 (highest in the 10 years of the kingbird research at MNWR) forced me 
to replace 20 of 65 ARTs at Buena Vista on 22 June. Water control structures prevented flooding at Bridge Creek, but I was also refused permission to canoe the creek until 22 June. Although I was concerned initially that my inability to check nests would compromise the experiment, it was not an issue because nesting was delayed (only three clutches were completed before I was able to begin nest checks), and thus flooding affected ARTs and NATs equally. To minimize disturbance to the nesting pair and the possibly of attracting predators to nests, I did not measure nest site characteristics until a nest either failed or fledged young.

\section{Nest site characteristics}

At all NATs, and both used and unused ARTs, I recorded the species of the tree and six nest placement variables: height of the nest above the ground (NESTHT); distance of the nest to the top of the tree (DISTTOP); horizontal distance of the nest to the center of the tree (DISTCENTR) and to the end of branch supporting the nest (DISENDBRN); angle in relation to horizontal of the main branch supporting the nest (ANGLEBRN); and cover around the nest (NESTCVR). I intended to calculate height of the nest above water, but this variable was dropped because of the constantly changing water levels. I measured NESTHT (from the bottom of the nest) for nests that overhung the water as the height of the nest above the riverbank adjacent to the spot where the tree was rooted. I used a rigid tape measure to take all linear measurements to the nearest 0.1 $\mathrm{m}$, and determined ANGLEBRN using a protractor attached to a level; angles of $0^{\circ}$ and $90^{\circ}$ corresponded to exactly horizontal and vertical branches, respectively. Branches that dipped below the horizontal plane yielded negative angles. I estimated NESTCVR by 
recording the number of times vegetation contacted the $1 \mathrm{~cm}$ marks of a $10 \mathrm{~cm}$ dowel held above and along the 4 cardinal directions around the nest. Maximum potential cover was thus 50. I also calculated the relative height of the nest in the tree (RELNESTHT = NESTHT/(NESTHT + DISTTOP) and relative distance of the nest to the canopy edge $($ RELDISCAN = DISENDBRN/(DISENDBRN + DISTCENTER).

\section{Statistical analysis}

Nest success was a binary variable defined as either the failure (i.e., no young fledged) or success of a nest ( $\geq 1$ young fledged). The few NATs located in trees far from water (i.e., > $100 \mathrm{~m}$ ) presented a different environment that could introduce variation that would compromise my ability to discern differences in nest placement between failed and successful nests along the relatively homogeneous riparian habitat. I therefore limited extraneous sources of variation by only including nests built within $\sim 15 \mathrm{~m}$ of the riparian zone in my analyses.

I arcsine transformed proportions. Examination of all other variables, with the exception of NESTHT and NESTCVR, showed that they were normally distributed. $\log _{10}$ transformation of NESTHT rectified that problem, but no transformation was able to correct the non-normal distribution of NESTCVR. However, NESTCVR's distribution was not egregiously far from normal, and because it was not a major component of variation in nest placement (see below), I used untransformed values of NESTCVR in my analyses. Population size was low in 2010 and 2011 compared to previous years (M. T. Murphy, unpubl. data). Consequently, many ARTs were not used because they were outside a kingbird territory. Average inter-nest distance at MNWR is 200 m (Redmond 
et al. 2009), and therefore I deemed any ART $\geq 200 \mathrm{~m}$ from a kingbird nest (ART or NAT) to be too isolated to be included in my analyses. By contrast, I considered all unused ARTs within $200 \mathrm{~m}$ of a NAT or used ART to be a rejected nest site. I then used Principal Component Analysis (PCA) of the eight nest placement variables to produce a multivariate description of nest position for the two categories of nests (NATs and ARTs), and to compare successful and failed nests. Means of nest placement variables and PCA axes with eigenvalues $>1.0$ were then made among NATs and used and unused ARTS, and for successful and failed NATs and used ARTs for PCA axes with eigenvalues > 1.0 using one-way analysis of variance (ANOVA).

Because nests were found (1) for all pairs, (2) prior to incubation for most, and (3) were checked every other day there was little concern that I failed to discover and include failed nests, or that differential exposure periods for different nests might bias comparisons of nest success among groups. Nevertheless, to account for the unlikely possibility that differential nest exposure might influence my conclusions, I used backwards elimination, stepwise logistic Mayfield regression to evaluate the extent to which success varied between years, nest type, or with nest placement while simultaneously accounting for nest exposure period (Hazler 2004).

Binary comparisons of nest success distinguish only between nests that fledged either 0 or $\geq 1$ nestling, but true reproductive success varied between 0 and 4 young. Hence, to explore the relationship between reproductive success and nest placement in greater detail I examined reproductive success of all nests in relation to year, nest type, and nest placement using best subsets analysis in an information theoretic framework. 
Akaike's Information Criterion, adjusted for small sample size (AICc), was used to evaluate model fit, with all models within two AICc units of the top model $(\triangle \mathrm{AICc}=0)$ considered candidate models of potential explanatory value. I then calculated model weights following methods outlined by Burnham and Anderson (2002). The importance of different parameters was judged by calculating their relative importance (Burnham and Anderson 2002) and by examining whether parameter estimates differed from zero (i.e., $90 \%$ confidence interval did not include 0 ). As a final analysis of reproductive success, I eliminated failed nests and tested for a relationship between number of young to fledge (1 to 4) and the same set of predictor variables used previously with the same statistical methods.

I used STATISTIX (Analytical software) for all analyses, and assumed statistical significance at $P \leq 0.05$. Statistics are reported as means $\pm \mathrm{SE}$.

\section{Results}

Nest site characteristics

Among natural nests within the riparian zone at Buena Vista and the main study area $(n=78)$, most were built in live or partially dead willow trees $(80.8 \%)$. The remainder were placed in rose bushes (Rosa sp.; 7.7\%), alder (Alnus spp.; 5.1\%), box elder (Acer negundo; 3.8\%), or sage brush (Artemisia sp. 2.6\%). Because artificial nests were placed in all of the latter except alders and box elders, I eliminated the seven nests 
placed in alders and box elders from the comparison of nest site characteristics of natural and artificial nests.

NATs were placed at $40 \%$ of tree height (i.e., $60 \%$ from the top) and within about $\sim 40 \%$ of the canopy edge when measured from the center of the tree. In absolute terms, however, NATs were closer to the canopy edge than to the top of the tree, and were also placed on an upward arching branch. NATs were placed absolutely and relatively higher in the tree than both used and unused ARTs, but in neither measure did used and unused ARTs differ (Table 3-1). By contrast, NATs and unused ARTs had similar distance to the top of tree, which was less than that of used ARTs. Similarly, the angle of the branch supporting the nest of NATs and unused ARTs did not differ, but branches supporting NATs were steeper than those supporting used ARTs. The absolute and relative position of NATs and ARTs on the horizontal plane differed little (Table 3-1) but, unused ARTs were absolutely closer to the center of the tree than either NATs or used ARTs. Given that maximum cover was 50, the low scores for all nest types indicated that nearly all nests were very exposed in the immediate area around the nest. Surprisingly, nest cover of used ARTs was significantly lower than that of both NATs and unused ARTs (Table 3-1). Contrary to my expectations, fewer differences in nest placement existed between NATs and unused ARTs (2) than between NATs and used ARTs (6).

Nest success and nest placement

Fewer nests fledged young in $2010(31.9 \%, \mathrm{n}=69)$ than in $2011(54.7 \%, \mathrm{n}=69$; $2 \times 2$ table, $\left.X^{2}=6.42, P=0.011\right)$ when all nests for both years were included. However, NATs $(40.9 \%, \mathrm{n}=88)$ and ARTs $(45.5 \%, \mathrm{n}=33)$ were equally likely to fledge young (2 
x 2 table, $\left.X^{2}=0.20, P=0.652\right)$. Predation accounted for $93.6 \%$ and $95.8 \%$ of failures in 2010 and 2011, respectively, and the failures of all ARTs. Nearly all failed NATs were attributable to predation $(92.3 \%, n=52)$; other causes of failure were weather $(n=2)$, human intervention $(\mathrm{n}=1)$, and abandonment $(\mathrm{n}=1)$.

Comparisons of the placement of successful and failed NATs and successful and failed ARTs showed similar patterns of difference between categories of success within a nest type (Table 3-2). For instance, although statistically significant only for NATs, successful NATs and ARTs were placed on limbs that were 2.35 times more vertically oriented (i.e., steeper angle to branch supporting nest) than failed nests within respective nest types (Table 3-2). Similarly, the absolute and relative height of successful NATs and successful ARTs tended to higher than failed nests. The absolute height of successful NATs was greater than that of failed, but not successful, ARTs, while relative nest height of successful NATs significantly exceeded that of both categories of ARTs (Table 3-2). The relatively higher placement of NATs, and tendency toward the same in successful nests, was also influenced by the absolute closer placement of NATs and successful nests to the top of the tree, with successful NATs again being placed significantly closer to the tree top than ARTs (Table 3-2). Thus, comparisons of nest angle and the three height related variables yielded the same pattern of difference between successful and failed nests for both NATs and ARTs; more successful nests tended to be more vertically oriented, placed higher in the tree and closer to the top.

Horizontal placement of nests showed fewer differences between the four combinations of nest type and nest fate. Distance to the end of the branch averaged $\sim 1.0$ 
$m$ in all four categories of nests, and neither it nor relative distance to the end of the branch (i.e., canopy edge) differed among the four nest type/success categories. However, successful NATs were placed closer to the center of the tree than failed ARTs (Table 32). Failed NATs and successful ARTs were intermediate and did not differ from each other or from successful NATs. Horizontal placement thus appeared to have weaker associations with success than vertical placement for both NATs and ARTs. The only variable to show an inconsistent pattern in the comparison of successful and failed nests between NATs and ARTs was nest cover; successful NATs and successful ARTs had the highest and lowest nest cover (differed significantly), respectively, of the four combinations of nest type and nest success (Table 3-2).

PCA of the nest variables yielded three axes with eigenvalues $>1.0$. PC1 described vertical dimensions of nest placement (Table 3-3). Positive scores corresponded to nests placed relatively and absolutely high in the tree and close to the top, on a vertically oriented branch that was close to the center of the tree. PC2 was a descriptor of variation in horizontal nest placement; nests with high positive scores were located absolutely and relatively far from the canopy and close to the center of the tree. Nest cover dominated the loadings on PC3 such that nests with high positive scores had low cover, but other variables contributed very little (Table 3-3). PC1 was the only axis along which the four combinations of nest type and nest success differed significantly ( $F$ $=8.10, \mathrm{df}=3,81, P<0.001)$, and in a clear and ordered fashion; successful NATs had the highest positive scores on PC1, followed by failed NATs, successful ARTs, and lastly by failed ARTs (Fig. 3-1). Failed NATs and successful ARTs did not differ from each, 
and neither differed from the other category of success within a nest type (for all, Tukey's test, $P>0.05$ ). However, successful NATs differed from failed ARTs (Tukey's test, $P<$ $0.05)$.

Nest success

Sample size was reduced from the previous comparisons of nest success and placement because it was impossible to determine exposure time for the logistic Mayfield exposure regression for four nests that failed at an undetermined point early in the nest cycle. Examination of nest success (successful $=0$, failed $=1$ ) in relation to year, nest type, and the eight nest placement variables as predictor variables showed that nest success was significantly more likely for nests placed in vertically oriented branches $(b=$ $-0.009, \mathrm{SE}=0.0043, P=0.037)$. No other variable was retained with angle of the nest branch angle in the model, but without it in the model, nests placed closer to the top of the tree were more likely to succeed $(b=0.25, \mathrm{SE}=0.126, P=0.047)$. Both variables loaded strongly on PC1 (Table 2), and were correlated with each other $(r=-0.502$, $\mathrm{df}=79, \mathrm{P}<0.001$ ), and therefore I entered PC1 as the only predictor variable to evaluate whether probability of failure was possibly predicted better by the constellation of variables on PC1 that reflected vertical dimensions of nest placement. Probability of failure decreased with increasing PC1 score (indicating that higher and more vertically oriented nests were more likely to succeed; $b=-0.16, \mathrm{SE}=0.082$ ), but the relationship was only marginally significant $(P=0.054)$. Hence, $P C 1$ 's correlated set of variables did not outperform either angle of the nest branch or distance of the nest from the top of the 
tree. Probability of nest success did not vary with either PC2 $(b=-0.06, \mathrm{SE}=0.121, P=$ $0.620)$ nor PC3 $(b=-0.103, \mathrm{SE}=0.138, P=0.456)$.

\section{Fledging success}

Measurement of nest success as a binary variable fails to account for variation in fledging success (i.e., number of fledglings). I therefore analyzed fledging success for nests that either failed ( 0 fledged young) or fledged young 1 to 4 young in relation to year, nest type, and the eight nest site variables using best subsets regression $(\mathrm{n}=85$ nests). $\triangle \mathrm{AICc}$ of seven models were within 2.0 AICc units of the top model (Table 3-4), indicating that model uncertainty was high. However, the top model of year and angle of the branch supporting the nest was 1.42 times more likely than the next best model, and it was the only individual model in which $95 \%$ confidence intervals of both parameter estimates did not include zero. Nest angle appeared in all eight models and had an importance weight of 1.001, while year was included in 6 of 8 models and had an importance weight of 0.786 (Table 3-4). The second ranked model included angle of the nest branch, year, and nest type. Nest type was included in 5 of 8 models, and had an importance rank of 0.578. Model-averaged parameter estimates across the eight competitive models indicated that angle of the nest branch and year were the only variables that did not include zero in the $90 \%$ confidence interval (Table 3-5).

The latter results were dominated by the high proportion of nests that failed entirely (63.5\% of 85 nests), and therefore I conducted a similar analysis to identify determinants of variation in productivity of successful nests. The top model of the eight with $\triangle$ AICc $<2$ included year, nest cover, and nest type, but it was only 1.11 and 1.37 
times more likely than the two next best models (Table 3-6). The second ranked model added relative distance of the nest to the end of the branch to the three variables in the top model, while the third ranked model included only year and nest cover (Table 3-6). The top model was at least 1.82 times more likely than the lowest five models. Year and nest cover occurred in all eight models (importance weight $=0.999$ for both), while nest type occurred in half the models (importance weight $=0.553$ ); no other variable had an importance weight $>0.396$. Model averaged parameter estimates for the eight models showed that $90 \%$ confidence intervals of parameter estimates of year, nest cover, and nest type did not included zero, but all others did (Table 3-5). Thus, number of young to fledge for successful nests increased with nest cover, was higher in 2011, and was greater in ARTs. Nest cover and year were the most important variables, and number of young to fledge increased equally with nest cover in both years (Fig. 3-2 equality of slopes: $F=$ $0.65, \mathrm{df}=1,27, P=0.426)$, but at any given level of cover, success was higher in 2011 (equality of elevation: $F=11.01, \mathrm{df}=1,28, P=0.002$ ).

\section{Discussion}

Natural nests of Eastern Kingbirds at MNWR were placed absolutely and relatively lower in trees compared to kingbirds breeding in Manitoba (MacKenzie and Sealy 1982), New York (Murphy 1983) and Kansas (Murphy 1983). By contrast, nests at MNWR and at the aforementioned sites were placed at nearly identical relative horizontal distances from the canopy edge. The differences in height exist, at least in part, because nesting kingbirds most often nest to riparian habitats in the extreme western portions of their geographic range (Csuti et al. 1997), and at MNWR, few trees in the riparian zone 
exceeded a height of $5 \mathrm{~m}$. In addition, many of the nest trees were rooted on the slope below the top of the riverbank. Under normal circumstances the base of the tree is above water, but because of the flooding I was forced to use the top of the riverbank as ground level. Thus, nest height in a normal year would have been 1 to $2 \mathrm{~m}$ higher, and closer to relative nest heights measured elsewhere (0.60 to 0.70; MacKenzie and Sealy 1982 , Murphy 1983). Nonetheless, I suspect that nests would have still been, on average, placed relatively lower in the tree at MNWR because, regardless of geographic location, female kingbirds in riparian and lacustrine habitats frequently place nests relatively low on branches that overhang water (Davis 1941, Blancher and Robertson 1985, M. T. Murphy, pers. observ.).

I attempted to distribute ARTs in locations that matched the natural placement of kingbird nests, but my results show that I was only partially successful. Most vertical dimensions of nest placement differed between NATs and ARTs, with the exception that NATs and unused ARTs were located similar distance from the top of the tree and also tended to be placed on more sharply angled branches than used ARTs. The difference between NATs and ARTs reflected the difficulty I had in placing ARTs at higher locations in trees over water in the floods of 2010 and 2011. By contrast, ARTs and NATs were positioned similarly along the horizontal plane, with the only difference being that unused ARTs were placed closer to the center of the tree than used ARTs.

Contrary to my predictions, there were more differences in nest placement between used and unused ARTs than between NATs and unused ARTs, and as a result, unused ARTs were in locations that tended to more closely match the sites chosen by 
kingbirds when they constructed their own nests. I suggest this paradoxical outcome has two possible and non-mutually exclusive explanations. First, kingbirds may have an inherent preference for sites that are either well up in trees on vertically oriented branches (MacKenzie and Sealy 1982, Murphy 1983), or on low, relatively horizontal branches that extend well out over water (Davis 1941, Blancher and Robertson 1985). The unused ARTs may have been located in less preferred intermediate positions and thus viewed as unacceptable. Second, it is almost a certainty that many females would have built NATs in lower positions overhanging water had they not used an ART. Most females with ARTs in their territory used them (Chapter 2), and thus the large difference in height and vertical orientation of NATs and used ARTs is probably exaggerated because most females that nested at lower heights used ARTs instead of building their own nest. Given this, and the fact that ARTs were of uniform design and quality as a nest structure, they provided an excellent opportunity to ask whether nest outcome was linked to nest placement, and if so, did the selected ARTs and NATs exhibit the same associations between success and placement? And, within both NATs and ARTs, was nest success more likely in nests with the seemingly preferred nest site characteristics?

\section{Nest success and nest location}

Nest success was lower in 2010 than 2011, but probability of whole nest failure did not differ between NATs and ARTs. As in all years (M. T. Murphy, unpubl. data), predation was nearly the only cause of nest failure at MNWR, and Black-billed Magpies (Pica hudsonia) and American Crows (Corvus brachyrhynchos) were the primary, if not the sole, nest predators. While poor weather (i.e., high winds and rain) often account for 
losses of many kingbird nests elsewhere (Murphy 1983, 2000), only 3\% of kingbird nest losses in 2010 and 2011 were attributable to weather, as is typical for this population (M. T. Murphy, unpubl. data).

Nest site selection is shaped presumably by the main factors causing nest failure, and as for kingbirds at MNWR, nest predation accounts for most nest losses among opencup nesting bird (Ricklefs 1969, Martin and Li 1992). Many studies have evaluated the expectation that sites chosen are those with the lowest probability of detection and/or destruction (e.g., Murphy 1983, Martin and Roper 1988, Wilson and Cooper 1998, Siepielski et al. 2002). Although some have argued that nest predation is so stochastic that selection for particular nest site attributes to reduce probability of predation is essentially impossible (Filliater et al. 1994), evidence in some species suggests that individuals adaptively modify nest placement in response to negative past experiences (Marzluff 1988, Forstmeier and Weiss 2004, Latiff et al. 2012). However, Chalfoun and Schmidt (2012) concluded from their literature review that most studies failed to detect positive relationships between nest placement and success. The poor fit was ascribed to many possible factors (see Chalfoun and Schmidt 2012), but two that seem particularly relevant here are temporal variation in the intensity of selection (i.e., temporal variation in predator abundance), and diversity of the predator community. Unpredictability of predator species identity, either because of the existence of a rich predator community or substantial fluctuation in nest predator numbers, should make it difficult for breeding birds to predictably identify secure nest sites because different predators may favor the use of different sites (Filliater et al. 1994). Nest failure may indeed be a largely stochastic 
event when a species faces a diversity of nest predators that vary from year-to-year in abundance, and as a consequence, I might expect a poor fit between the sites chosen for nests and the probability of success.

Among Eastern Kingbirds at MNWR, six of the eight comparisons of nest placement variables among the four groups created by the combination of nest type (NAT and ART) and nest fate yielded significant differences. The exceptions were the two variables describing horizontal placement in relation to canopy edge. Nest cover differed among groups, but given the low scores for all groups (Table 3-2) in comparison to the maximum possible (50), and the fact that the significant difference was between the two categories of successful nests, it seems likely that cover had little to do with the probability of success or failure of an entire nest, contrary to studies of kingbirds in New York and Kansas (Murphy 1983) and of a number of other species as well (Santisteban et at. 2002, Latif et at. 2012; but see Howlett and Stutchbury 1996).

Four of the five remaining variables that exhibited significant differences among groups were components of vertical nest placement. None of the variables differed significantly between failed and successful ARTs, and only one (angle of the nest branch) differed between failed and successful NATs, and therefore most of the statistical significance was a product of comparisons between NATs and ARTs. However, of note is the fact that the pattern of difference between successful and failed NATs and successful and failed ARTs was the same for angle of the branch, the three variables describing vertical placement, and distance to center of tree; successful NATs and ARTs tended to be placed higher in the tree on more steeply angled branches, and closer to the 
center of the tree than their failed counterparts. The association of success with height is not uncommon (Wilson and Cooper 1998, Burhans et al. 2002, Vanderwerf 2012), presumably because it places nests above the activity range of many nest predators. Kingbird nest success was thus associated with the same set of variables that contributed most heavily to PC1, the major gradient of variation in nest placement. Indeed, scores of successful NATs on PC1 were significantly higher than the scores of failed ARTs, failed NATs and successful ARTs were intermediate, and scores of successful nests of both nest types tended to be higher than their failed counterparts. These patterns indicate that kingbird nest success was positively associated with the major gradient describing differences in nest placement. My placement of the ARTs pushed the limits of where kingbirds normally place their nests, but they were used, and the most extreme of these failed. I interpret this as support for the hypothesis that kingbird nest placement was adaptive.

Simultaneous evaluation of the contribution of each variable to nest success (i.e., failed or successful) using logistic regression suggested that the angle of the branch on which the nest was placed was the primary determinant of success; probability of success increased as the supporting branch became increasingly vertical. Without nest branch angle in the model, nests placed closer to the top were most likely to succeed. Analyses based on the number of young to fledge also showed that angle of the nest branch was the best predictor of fledging success, followed by year, and possibly nest type. However, differences in fledging success among successful nests (both NATs and ARTs) yielded a somewhat different result; fledging success again varied with year, but success now 
increased with nest cover, and ARTs fledged more young than NATs. The absence of an association between nest cover and success of entire nests may be because virtually all kingbird nests at MNWR are quite exposed and other factors thus have a greater influence on the probability that a predator locates a nest. However, among nests that escaped predation, differences in nest cover may affect microclimate to the degree that it influences physical stress on the young and parental behavior. Kingbird nests are often directly exposed to sunlight, and the high temperatures and high insolation of midsummer may force parents of nests with low nest cover to stay at the nest to shade young rather than forage for food. That successful ARTs had the lowest cover argues against this hypothesis, but the lower placement of ARTs means that more vegetation existed above the nest to provide incidental shade. Furthermore, ARTs generally had deeper nest cups than NATs, and this too would have provided shade, which possibly explains why fledging success was higher in ARTs than NATs. That the highest nest cover exhibited by the four combinations of nest type and outcome was present in successful NATs suggests that, given full freedom of choice, kingbirds selected sites that yielded the highest fledging success.

Kingbirds are known for their very active nest defense and unrelenting attacks on potential nest predators (Davis 1955, Blancher and Robertson 1982, Siderius 1993, Redmond et al. 2009). At MNWR, the only potential mammalian predators are longtailed weasels (Mustela frenata) and possibly mink (M. vision), and video of parental behavior showed that kingbirds can drive weasels away from nests (M. T. Murphy, pers. comm.). Three species of constricting snakes that might prey upon kingbird eggs and 
young occur at MNWR. Garter snakes (Thamnophis spp.) are more aquatic than arboreal, but gopher snakes (Pituophis catenifer) and yellow-bellied racers (Coluber constrictor) can climb well and do prey on nestling passerines (Eichholz and Koenig 1992, Burhans et al. 2002). In Missouri, nest success of Indigo Buntings (Passerina cyanea) and Field Sparrows (Spizella pusilla) increased with nest height, probably because yellow-bellied racers (a common nest predator) did not usually climb above the level of low shrubs (Burhans et al. 2002). I never observed either gopher snakes or racers off the ground, and only rarely have they been seen in trees at MNWR (M. T. Murphy, pers. comm.). Placement of nests well up in tree, or well out on horizontal limbs, probably reduces the likelihood that either mammalian or reptilian snake predators destroy kingbird nests, and would also enable kingbirds to effectively utilize their excellent flight abilities to defend nests against avian predators.

Black-billed Magpies are the most important predator on kingbird nests at MNWR, and on three occasions they took nestlings during filming of parental kingbird behavior. Kingbirds also always respond very aggressively to their presence and vocalizations. The low diversity of nest predators at MNWR thus eliminates a major obstacle to selection for adaptive nest placement. Coupled with the fact that kingbirds are capable nest defenders, the consistent pattern seen in both NATs and ARTs for successful nests to be placed higher in the tree and on more vertically oriented limbs than failed nests, suggests that kingbirds selected sites with a higher probability of success, and lends credence to the hypothesis that nest site selection in birds is largely shaped by the major factors causing nest mortality. 
Table 3.1. Nest placement statistics for Eastern Kingbirds at Malheur National Wildlife Refuge, Oregon (2010-2011). Clutches were laid in nests either built by female Eastern Kingbirds or in artificial nests that were provided and females chose to use. Statistics for unused artificial nests located within 200 m of a nesting pair of Eastern Kingbirds are also provided. Results of analysis of variance reported $(F[P])$, and nest success/nest type categories that share a letter do not differ significantly. Sample sizes in parentheses.

\begin{tabular}{|c|c|c|c|c|}
\hline Variable & Natural (64) & Used ART (35) & Unused Art (67) & $F(P)$ \\
\hline Angle of branch & 34.3 (4.33)A & $15.5(5.86) \mathrm{B}$ & $25.8(4.32) \mathrm{AB}$ & $3.39(0.036)$ \\
\hline Relative height & $0.40(0.032) \mathrm{A}$ & $0.14(0.044) \mathrm{B}$ & $0.18(0.032) \mathrm{B}$ & $17.74(0.000)$ \\
\hline Nest height & $1.61(0.144) \mathrm{A}$ & $0.47(0.194) \mathrm{B}$ & $0.68(0.140) \mathrm{B}$ & $15.48(0.000)$ \\
\hline Distance to top & $1.98(0.138) \mathrm{A}$ & $2.91(0.187) \mathrm{B}$ & $2.31(0.135) \mathrm{A}$ & $8.02(0.001)$ \\
\hline Relative distance & $0.43(0.025)$ & $0.39(0.033)$ & $0.44(0.024)$ & $0.82(0.440)$ \\
\hline Distance to end & $1.00(0.057)$ & $1.18(0.077)$ & $1.05(0.056)$ & $1.85(0.160)$ \\
\hline Distance to center & $1.72(0.137) \mathrm{AB}$ & $2.12(0.185) \mathrm{B}$ & $1.55(0.134) \mathrm{A}$ & $3.10(0.048)$ \\
\hline Nest cover & $1.92(0.270) \mathrm{A}$ & $0.77(0.365) \mathrm{B}$ & $1.82(0.264) \mathrm{A}$ & $3.62(0.029)$ \\
\hline
\end{tabular}


Table 3.2. Nest placement statistics (mean [SE]) for failed and successful Eastern Kingbird breeding attempts that were made in either natural or artificial nests at Malheur National Wildlife Refuge (2010-2011). Results of analysis of variance reported are given $(F[P])$. Categories of nest type and nest success that share a letter (A, B, or C) do not differ significantly. Sample sizes in parentheses.

\begin{tabular}{|c|c|c|c|c|c|}
\hline \multirow[b]{2}{*}{ Variable } & \multicolumn{2}{|c|}{ Natural nests } & \multicolumn{2}{|c|}{ Artificial nests } & \multirow[b]{2}{*}{$F(P)$} \\
\hline & Failed (33) & Successful (19) & Failed (20) & Successful (13) & \\
\hline Angle of branch & 21.8 (5.97)B & $51.2(7.86) \mathrm{A}$ & $10.4(7.66) \mathrm{B}$ & $24.8(9.50) \mathrm{AB}$ & $4.97(0.003)$ \\
\hline Relative height & $0.31(0.046) \mathrm{AB}$ & $0.44(0.060) \mathrm{A}$ & $0.12(0.059) \mathrm{B}$ & $0.20(0.073) \mathrm{B}$ & $5.36(0.002)$ \\
\hline Nest height & $1.17(0.186) \mathrm{A}$ & $1.64(0.245) \mathrm{A}$ & $0.34(0.239) \mathrm{B}$ & $0.72(0.296) \mathrm{AB}$ & $5.41(0.002)$ \\
\hline Distance to top & $2.30(0.204) \mathrm{AB}$ & $1.58(0.269) \mathrm{B}$ & $3.05(0.263) \mathrm{A}$ & $2.74(0.326) \mathrm{A}$ & $5.55(0.002)$ \\
\hline Relative distance & $0.43(0.034)$ & $0.45(0.044)$ & $0.35(0.043)$ & $0.43(0.053)$ & $1.21(0.313)$ \\
\hline Distance to end & $1.02(0.076)$ & $0.98(0.100)$ & $1.12(0.098)$ & $1.16(0.122)$ & $0.72(0.544)$ \\
\hline Distance to center & $1.71(0.192) \mathrm{AB}$ & $1.44(0.252) \mathrm{B}$ & $2.44(0.246) \mathrm{A}$ & $1.71(0.305) \mathrm{AB}$ & $3.04(0.034)$ \\
\hline Nest cover & $1.76(0.349) \mathrm{AB}$ & $2.16(0.460) \mathrm{A}$ & $1.20(0.448) \mathrm{AB}$ & $0.15(0.556) \mathrm{B}$ & $2.96(0.037)$ \\
\hline
\end{tabular}


Table 3.3. Factor loadings, eigenvalues, and proportion of the variance explained by the first three axes from the principal component analysis of nest placement variables for natural and used artificial nests of Eastern Kingbirds breeding at Malheur National Wildlife Refuge.

\begin{tabular}{|c|c|c|c|}
\hline Variable & PC1 & $\mathrm{PC} 2$ & PC3 \\
\hline Nest angle & 0.385 & 0.165 & 0.278 \\
\hline Relative nest height & 0.468 & -0.241 & 0.182 \\
\hline Nest height (m) & 0.417 & -0.303 & 0.287 \\
\hline Distance of nest to top & -0.417 & 0.118 & 0.173 \\
\hline Relative distance to end of branch & 0.274 & 0.607 & -0.132 \\
\hline Distance to end of branch & -0.174 & 0.531 & 0.280 \\
\hline Distance to center of tree & -0.399 & -0.396 & 0.097 \\
\hline Nest cover & 0.141 & -0.042 & -0.820 \\
\hline Eigenvalue & 3.441 & 1.503 & 1.032 \\
\hline Explained variance $(\%)$ & 42.6 & 18.8 & 12.9 \\
\hline$\Sigma$ Explained variance $(\%)$ & 42.6 & 61.4 & 74.3 \\
\hline
\end{tabular}


Table 3.4. Model selection table summarizing results of the analysis of number of young to fledge (0 to 4) from Eastern Kingbirds nests at Malheur National Wildlife Refuge, OR. Predictor variables included year, nest type, and eight nest placement variables. Number of parameters $(K)$, the difference in Akaike Information Criterion (corrected for small sample size; $\triangle \mathrm{AICc}$ ) between the top and other models, and model weights $\left(w_{i}\right)$ are given for the eight models with $\triangle \mathrm{AICc} \leq 2$ ), along with the proportion of the variation accounted for by each model $\left(R^{2}\right)$.

\begin{tabular}{|c|c|c|c|c|}
\hline Model & $K$ & $\triangle \mathrm{AICc}$ & $\mathrm{W}_{\mathrm{i}}$ & $R^{2}$ \\
\hline Angle + year & 4 & 0.000 & 0.211 & 0.146 \\
\hline Angle + year + nest type & 5 & 0.692 & 0.149 & 0.162 \\
\hline Angle + year + nest type + distance to top & 6 & 0.936 & 0.132 & 0.182 \\
\hline Angle + nest type + dist top & 5 & 1.034 & 0.126 & 0.154 \\
\hline Angle + year + dist end & 5 & 1.376 & 0.106 & 0.155 \\
\hline Angle + year + dist top & 5 & 1.377 & 0.106 & 0.155 \\
\hline Angle + nest type & 4 & 1.743 & 0.088 & 0.128 \\
\hline Angle + year + nest type + distance to end & 6 & 1.856 & 0.083 & 0.173 \\
\hline
\end{tabular}


Table 3.5. Model averaged estimates $(b)$ and SE (in parentheses), and $90 \%$ confidence intervals for variables that contributed to the top models (i.e., AICc < 2.0) of variation in fledging success for Eastern Kingbirds at Malheur National Wildlife Refuge, Oregon, in 2010 and 2011. Fledging success varied from 0 to 4 young (= Failed and successful nests) or 1 to 4 young (= successful nests). Dashed lines (- indicate that the variable did not contribute to a final model.

Failed and successful nests

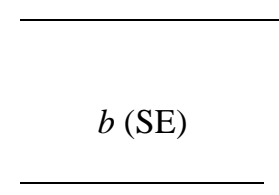

Intercept

Angle

Year

Cover

Nest type

Distance from top

Distance to end

Relative distance end

Nest height

Relative nest height
$-931.3(811.6)$

$0.011(0.005)$

$0.658(0.337)$

0.567 (0.367)

$-0.192(0.147)$

$-0.355(0.365)$

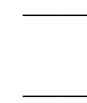

$-0.862(0.644)$
$90 \% \mathrm{CI}$

-

-2266.4 to 403.7

0.0036 to 0.0188

0.104 to 1.212

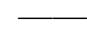

-0.036 to 1.170

-0.434 to 0.051

-0.955 to 0.245

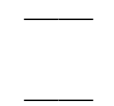

-1.919 to 0.199
Successful nests

\begin{tabular}{cc}
\hline \multicolumn{1}{c}{$b(\mathrm{SE})$} & $90 \% \mathrm{CI}$ \\
\cline { 2 - 2 }$-2116.8(791.0)$ & -3418 to -815 \\
$0.054(0.394)$ & 0.406 to 1.701 \\
$0.241(0.094)$ & 0.087 to 0.396 \\
$0.727(0.403$ & 0.390 to 1.390 \\
$-0.227(0.215)$ & -0.584 to 0.124
\end{tabular}

0.933 (0.609)

-0.068 to 1.935

$-0.180(0.163)$

-0.447 to 0.088 
Table 3.6. Model selection table summarizing results of the analysis of number of young to fledge from successful (1 to 4) Eastern Kingbirds nests at Malheur National Wildlife Refuge, OR. Predictor variables included year, nest type, and eight nest placement variables. Number of parameters $(K)$, the difference in Akaike Information Criterion (corrected for small sample size; $\triangle \mathrm{AICc}$ ) between the top and other models, and model weights $\left(w_{i}\right)$ are given for the eight models with $\left.\Delta \mathrm{AICc} \leq 2\right)$, along with the proportion of the variation accounted for by each model $\left(R^{2}\right)$.

\begin{tabular}{|c|c|c|c|c|}
\hline Model & $K$ & $\triangle \mathrm{AICc}$ & $\mathrm{W}_{\mathrm{i}}$ & $R^{2}$ \\
\hline Cover + year + nest type & 5 & 0.000 & 0.206 & 0.379 \\
\hline Cover + year + type + relative distance end & 6 & 0.209 & 0.186 & 0.435 \\
\hline Cover + year & 4 & 0.631 & 0.150 & 0.305 \\
\hline Cover + year + relative distance end & 5 & 1.207 & 0.113 & 0.355 \\
\hline Cover + year + relative nest height & 5 & 1.506 & 0.097 & 0.348 \\
\hline Cover + year + nest height & 5 & 1.735 & 0.087 & 0.344 \\
\hline Cover + year + type + distance to top & 6 & 1.795 & 0.084 & 0.405 \\
\hline Cover + year + type + nest height & 6 & 1.956 & 0.077 & 0.402 \\
\hline
\end{tabular}


Figure 3.1. Box-and-whisker plot of PC1 compared to different categories of nest success and nest type for Eastern Kingbirds breeding at Malheur National Wildlife Refuge, OR from 2010 and 2011. Horizontal lines represent medians, boxes enclose the middle $50 \%$ of observations, vertical lines represent the $10^{\text {th }}$ and $90^{\text {th }}$ percentiles, and stars are observations outside the latter limits.

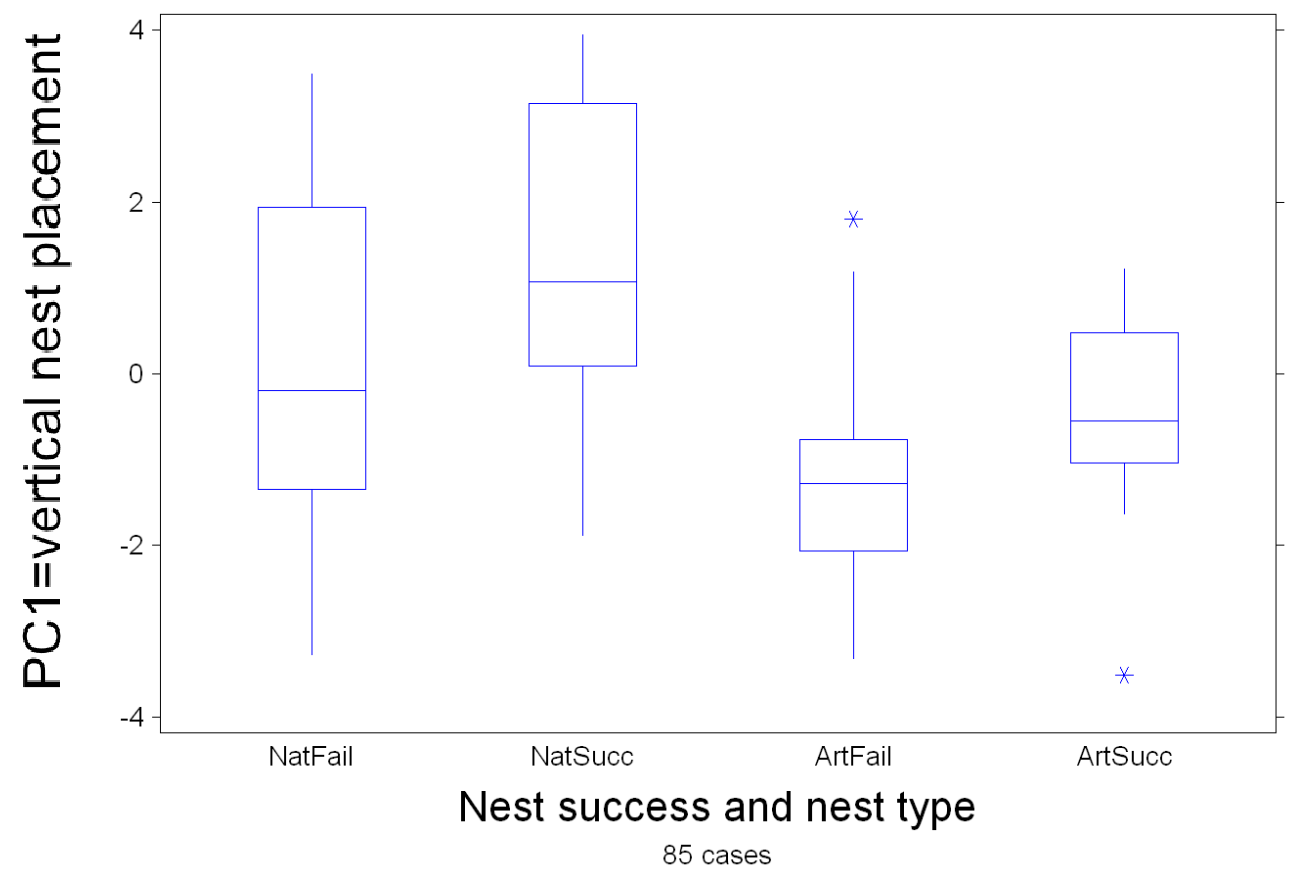


Figure 3.2. Fledging success of Eastern Kingbird nests at Malheur National Wildlife Refuge from 2010 and 2011 in relation to vegetation cover in the $10 \mathrm{~cm}$ sphere surrounding the nest.

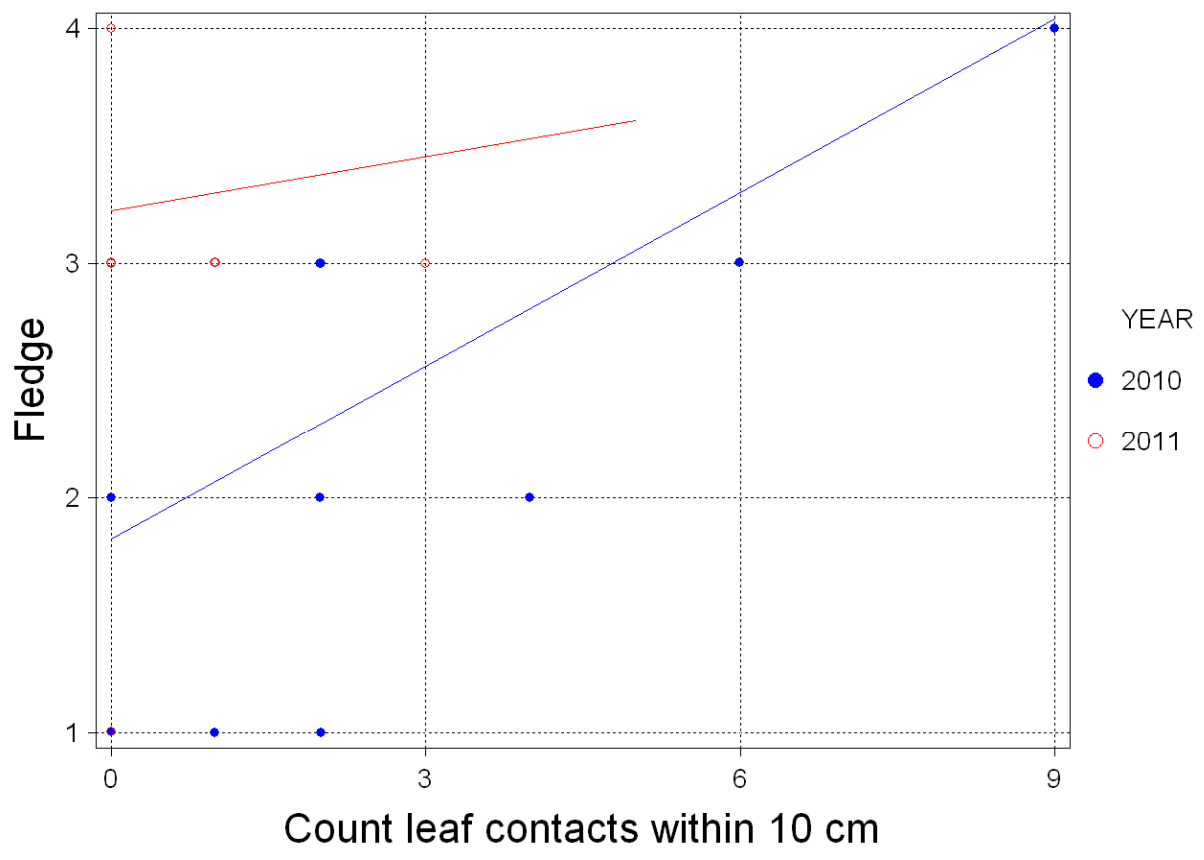




\section{CHAPTER 4: CONCLUSIONS}

I used an experimental approach to study nest reuse and nest site selection in a breeding population of Eastern Kingbirds (hereafter kingbirds) at Malheur National Wildlife Refuge (MNWR) for two years, 2010 and 2011. Mine was one of the first studies in an open-cup nesting passerine to use artificial nests to experimentally address questions involving nest reuse or nest placement.

MNWR's high elevation location and consequent delayed spring phenology further shortens the already generally short breeding season of kingbirds. The shorter breeding season is associated with smaller clutch sizes (Weeks 1978; Eberhardt 1994 in Walters et al. 2002; but see Conrad \& Robertson 1993) and a reduced probability of replacing failed first nesting attempts. Thus, nest reuse may benefit kingbirds by reducing energy demands so they can hasten clutch initiation to begin egg-laying. Nest building is costly and not surprisingly, the construction of NATs required a third more material than what was needed to line an ART, and most likely took more time to build. However, this may not translate into a third less energy because the outer lining is composed of larger materials, while the inner lining has finer material. Therefore, it is likely that the two do not require equal effort to build. Females can be very selective of nesting materials, and depending upon availability, may make long flights to collect specific material for either the outer shell or lining (Murphy 1996a). Since it is known that nests are costly to construct, I assessed the differences of reproductive parameters between ARTs and NATs. 
I found that kingbirds who used an ART did not exhibit significant differences with NATs in timing of breeding, clutch size, egg mass, incubation period, number of eggs to hatch, or number of young to fledge. Those findings led me to reject the hypothesis that an advantage of nest reuse is that it saves time and/or energy. The only variable to suggest a possible advantage of nest reuse was that if a nest failed, it took the female a shorter amount of time to lay a replacement clutch if she used an ART instead of building a NAT. An additional finding that supports my rejection of the hypothesis that nest reuse is a time saving mechanism is that ARTs were used more often in the 2011 breeding season, which was significantly earlier than the 2010 breeding season. This completely contradicts predictions of the time-energy savings hypothesis. By default, I argue that the evidence is consistent with the hypothesis that quality nest sites are limited at MNWR. The pre-laying period of 2011 also experienced heavy flooding, to the point where I was denied access to canoe the river and check on nests. When access was granted many of the ARTs on low branches were submerged. The fact that ARTs on low branches became submerged suggests that many of the low hanging branches that kingbirds use were also unavailable because they were under water for most of the prelaying period. This probably exacerbated the already limited availability of suitable nest sites, and may explain why nest reuse was so common in 2011. I also documented other species (American Robin, Mourning Dove, Tree Swallow) using the ARTs, which also suggests that suitable nest sites for many other species along the river are limited. I first explored differences in the nest site structure between ARTs and NATs. 
I used the existing ARTs to assess differences in nesting structure at the level of the nest site between used and unused ARTs and NATs. I was partially successful in distributing ARTs in locations similar to those that kingbirds use. NATs and unused ARTs had a similar vertical placement, were on more sharply angled branches, and had more cover than used ARTs. The unused ARTs were in locations that more closely matched natural sites chosen by kingbirds. This could be due to unused ARTs being located in less preferred intermediate positions. Alternatively, females could have built NATs in lower positions overhanging water, had they not used an ART and most females with ARTs in their territories used one. I also determined if kingbirds are making adaptive nest site choices, in which case they would choose locations that results in higher reproductive success.

Nest predation accounted for the majority of nest failures at MNWR in both 2010 and 2011. The main nest predators to kingbirds at MNWR are the Black-billed Magpie and the American Crow. The low diversity of nest predators eliminates an obstacle to selection for adaptive nest placement. Kingbirds are capable nest defenders and there is a consistent pattern that successful NATs and ARTs were placed higher in the tree and on more sharply angled limbs than failed nests in both NATs and ARTs. This suggests that kingbirds selected nest sites that were more likely to fledge young. Nests higher in the tree may allow the kingbird to better defend its nest (Ricklefs 1977, Murphy et al.1997). Elsewhere, higher nests placed in a tree have been associated with greater nest success, most likely because ground predators have a difficult time reaching higher nests (Murphy 1983, Wilson and Cooper 1998, Burhans et al. 2002). My findings also provide support to 
the hypothesis that nest site selection in birds is greatly shaped by the major factors causing nest mortality. Nest cover is another variable that has been found to be an important factor for nest success in birds.

I did not find any indication that nest success (i.e., fledging of $\geq 1$ young) was more likely for nests with high nest cover, most likely because virtually all kingbird nests at MNWR were exposed and other factors had a greater influence on the probability that a predator located a nest. Among successful nests (both NATs and ARTs), the number of young to fledge (1 to 4) was higher in 2011, and was also higher in nests with greater nest cover, and in ARTs. Among nests that escaped predation, differences in nest cover may affect the microclimate to the degree that it influences physical stress on the young and parental behavior. Kingbird nests are often directly exposed to sunlight and the high temperatures of summer may force parents of nests with low cover to stay at the nest to shade young rather than forage for food. Successful ARTs were found to have the lowest cover, which argues against that hypothesis. However, ARTs were placed lower in trees, which means that more vegetation existed above the nest to provide incidental shade. Furthermore, ARTs generally had deeper nest cups than NATs, and this too would have provided shade, which possibly explains why fledging success was higher in ARTs than in NATs. The highest nest cover exhibited by the four nest type combinations was found in successful NATs, which suggests that, given full freedom of choice, kingbirds selected sites that yielded the highest fledging success.

Further work should address the number of trips a female makes to construct her nest to determine how much time and energy is invested into building an open-cup nest. 
Also, it would be extremely useful to test the time and energy savings and nest site shortage hypotheses on kingbirds where nest reuse has not been reported; if made available, would kingbirds use ARTs where quality nest sites exist in abundance? It would be beneficial to perform the experiment a third year during more normal weather conditions to compare it to the two years. Further studies could expand on this research by taking vegetation measurements on random plots and examining the total coverage surrounding the nest. Further work could map the territories of Black-billed Magpies at MNWR to estimate their abundance and relate that to kingbird fitness. 


\section{REFERENCES}

Analytical Software. 2009. STATISTIX. Tallahassee, FL.

Bears, H., K. Martin \& White, G. C. 2009. Breeding in high-elevation habitat results in shift to slower life-history strategy within a single species. Journal of Animal Ecology 78:365-375.

Bergin, T. M. 1997. Nest reuse by Western Kingbirds. Wilson Bulletin 109:735-737.

Blancher, P. J., and R. J. Robertson. 1982. Kingbird aggression: does it deter predation? Animal Behaviour 40:929-930.

Blancher, P. J. \& R. J. Robertson. 1985. Site consistency in kingbird breeding performance: Implications for site fidelity. Journal of Animal Ecology 54:10171027.

Brawn, J. D. \& Balda, R. P. 1988. Population biology of cavity nesters in northern Arizona: Do nest sites limit breeding densities? Condor 90:61-71.

Brown, C. R. \& Bomberger Brown, M. 1986. Ectoparasitism as a cost of coloniality in Cliff Swallows (Hirundo pyrrhonota). Ecology 67:1206-1218.

Brown, C. R. \& Bomberger Brown, M. 1996. Coloniality in the Cliff Swallow: The Effect of Group Size on Social Behavior. Chicago: University of Chicago Press.

Burhans, D. E., D. Dearborn, F. R. Thompson III, and J. Faaborg. 2002. Factors 
affecting predation at songbird nests in old fields. Journal of Wildlife Management 66:240-249.

Burnham, K. P. and D. R. Anderson. 2002. Model selection and multimodel inference: A practical information - Theoretic Approach, second edition. Springer.

Cavitt, J. F., Pearse, A. T \& Miller, T. A. 1999. Brown Thrasher nest reuse: A time saving resource, protection from search-strategy predators, or cues for nest-site selection? Condor 101:859-862.

Chalfoun, A. D., and K. A. Schmidt. 2012. Adaptive breeding-habitat selection: Is it for the birds? Auk 129:589-599.

Colias, N. E. and E. C. Colias. 1984. Nest building and bird behavior. Princeton University Press.

Conrad, K. F., \& Robertson, R. J. 1993. Clutch size in eastern phoebes (Sayornis phoebe). I. The cost of nest building. Canadian Journal of Zoology 71:10031007.

Cooper, N. W., Murphy, M. T., Redmond, L. J. \& Dolan, A. C. 2011. Reproductive correlates of spring arrival date in the Eastern Kingbird Tyrannus tyrannus. Journal of Ornithology 152:143-152. 
Csuti, B., A. J. Kimerling, T. A. O’Neil, M. M. Shaughnessy, E. P. Gaines, and M. M. P. Huso. 1998. Atlas of Oregon Wildlife: Distribution, Habitat, and Natural History. Oregon State University Press, Corvallis, Oregon.

Curson, D. R. Goguen, C. B, \& Matthews, N. E. 1996. Nest-site reuse in the Western Wood-Pewee. Wilson Bulletin 108:378-380.

Davies, N. B. \& Lundberg, A. 1985. The influence of food on time budgets and timing of breeding of the Dunnock Prunella modularis. Ibis 127:100-110.

Davis, D. E. 1941. The belligerency of the kingbird. Wilson Bulletin 53:157 - 168.

Davis, D.E. 1955. Observations on the breeding biology of kingbirds Condor 57:208 212.

Dobkin, D. S., Rich, A. C., Pretare, J. A. \& Pyle, W. H. 1995. Nest-site relationships among cavity-nesting birds of riparian and snowpocket aspen woodlands in the northwestern Great Basin. Condor 97:694-707.

Dolan, A. C., Murphy, M. T., Redmond, L. J. \& Duffield, D. 2009. Maternal characters and the production and recruitment of sons in the eastern kingbird (Tyrannus tyrannus). Behavioral Ecology and Sociobiology 63:1527-1537.

Eberhardt, L. S. 1994. Sap feeding and its consequences for reproductive success and communication in Yellow-bellied Sapsuckers (Sphyrapicus varius). Ph.D. thesis, University of Florida. 
Eggers, S., M. Griesser, and J. Ekman. 2005. Predator-induced plasticity in nest visitation rates in the Siberian Jay (Perisoreus infaustus). Behavioral Ecology 16:309-315.

Eichholz, M. W., and W. D. Koenig. 1992. Gopher snake attraction to birds' nests. Southwestern Naturalist 37:293-298.

Ellison, K. S. 2008. Nest reuse by Vermillion Flycatchers in Texas. Wilson Journal of Ornithology 120:339-344.

Filliater, T. S., R. Breitwisch, and P. M. Nealen. 1994. Predation on Northern Cardinal nests: Does choice of nest site matter? Condor 96:761-768.

Fontaine, J. J., and T. E. Martin. 2006. Parent birds assess nest predation risk and adjust their reproductive strategies. Ecology Letters 9:428-434.

Forstmeier, W. and I. Weiss. 2004. Adaptive plasticity in nest-site selection in response to changing predation risk. Oikos 104:487-499.

Friesen, L. E., Wyatt, V. E. \& Cadman, M. D. 1999. Nest resuse by Wood Thrushes and Rose-breasted Grosbeaks. Wilson Bulletin 111:132-133.

Gaston, A. J., Gilchrist, H. G. \& Hipfner, J. M. 2005. Climate change, ice conditions and reproduction in an Arctic nesting marine bird: Brunnich's Guillemot (Uria lomvia L.). Journal of Animal Ecology 74:832-841. 
Gautheir, M. \& Thomas, D. W. 1993. Nest site selection and cost of nest building by Cliff Swallows (Petrochelidon pyrrhonota). Canadian Journal of Zoology 71: $1120-1123$.

Gill, S. A. \& Stutchbury, B. J. M. 2005. Nest building is an indicator of parental quality in the monogamous Neotropical Buff-breasted Wren (Thryothorus leucotis). Auk 122:1169-1181.

Götmark, F., D. Blomqvist and O. C. Johansson and J. Bergkvist. 1995. Nest site selection: A trade-off between concealment and view of the surroundings? Journal of Avian Biology 26:305-312.

Hansell, M. 2000. Bird nests and construction behavior. Cambridge: Cambridge University Press.

Hatch, M. I. 1997. Variation in Song Sparrow nest defense: individual consistency and relationship to nest success. Condor 99:282-289.

Hazler, K. R. 2004. Mayfield logistic regression: A practical approach for analysis of nest survival. Auk 121:707-716.

Hauber, M. E. 2002. Is reduced clutch size a cost of parental care in Eastern Phoebes (Sayornis phoebe)? Behavioral Ecology and Sociobiology 51:503-509.

Holway, D. A. 1991. Nest-site selection and the importance of nest concealment in the 
Black-throated Blue Warbler. Condor 93:575-581.

Howlett, J. S. and B. J. Stutchbury. 1996. Nest concealment and predation in Hooded Warblers: Experimental removal of nest cover. Auk 113:1-9.

Johnston, D. W. 1971. Niche relationships among some deciduous flycatchers. Auk 88:796-804

Kelly, J. F. \& Van Horne, B. 1997. Effects of food supplementation on the timing of nest initiation in Belted Kingfishers. Ecology 78:2504-2511.

Lack, D. 1968. Ecological adaptations for breeding in birds. Methuen Press, London.

Latif, Q. S., S. K. Heath and J. T. Rotenberry. 2012. How avian nest site selection responds to predation risk: testing an 'adaptive peak hypothesis.' Journal of Animal Ecology 81:127-138.

Lens, L., Wauters, L. A. \& Dhondt, A. A. 1994. Nest building by crested tit Parus cristatus males: an analysis of costs and benefits. Behavioral Ecology and Sociobiology 35:431-436.

MacKenzie, D. I. \& Sealy, S. G. 1981. Nest site selection in Eastern and Western Kingbirds: A multivariate approach. Condor 83:310-321.

Martin, T. E. 1992. Interaction of nest predation and food limitation in reproductive strategies. Current Ornithology 9:163-197.

Martin, T. E. 1993. Nest predation and nest sites. Bioscience 43:523-532. 
Martin, T. E. and J. J. Roper. 1988. Nest predation and nest-site selection of a Western population of the Hermit Thrush. Condor 90: 51-57.

Martin, T. E. and P. Li. 1992. Life history traits of open - vs. cavity nesting birds. Ecology 73:579-592.

Martin, K. \& Wiebe, K. L. 2004. Coping mechanisms of alpine and arctic breeding birds: Extreme weather and limitations to reproductive resilience. Integrative and Comparative Biology 44:177-185.

Marzluff, J. M. 1988. Do pinyon jays alter nest placement based on prior experience? Animal Behaviour 36:1-10.

Montgomerie, R. D. and P. J. Weatherhead. 1988. Risks and Rewards of nest defence by parent birds. The Quarterly Review of Biology 63:167-187

Moreno, J., Martínez, J., Corral, C., Lobato, E., Merino, S., Morales, J., Martínez- De La Puente, J. \& Tomás, G. 2008. Nest construction rate and stress in female Pied Flycatchers Ficedula hypoleuca. Acta Ornithologica 43:57-64.

Mountjoy, D. J. \& Robertson, R. J. 1988. Nest-construction tactics in the Cedar Waxwing. Wilson Bulletin 100:128-130.

Murphy, M. T. 1981. Growth and aging of nestling Eastern Kingbirds and Eastern Phoebes. Journal of Field Ornithology 52:309-316. 
Murphy, M. T. 1983. Nest success and nesting habits of Eastern Kingbirds and other flycatchers. Condor 85:208-219.

Murphy, M. T. 1986. Temporal components of reproductive variability in Eastern Kingbirds (Tyrannus tyrannus). Ecology 67:1483-1492.

Murphy, M. T. 1996a. Eastern Kingbird (Tyrannus tyrannus). In The Birds of North America, Philadelphia: The Academy of Natural Sciences; Washington D.C.: The American Ornithologists' Union.

Murphy, M. T. 1996b. Survivorship, breeding dispersal and mate fidelity in Eastern Kingbirds. Condor 98:83-93

Murphy, M. T. 2000. Evolution of clutch size in the Eastern Kingbird: tests of alternative hypotheses. Ecological Monographs 70:1-20.

Murphy, M. T. 2004. Intrapopulation variation in reproduction by Eastern Kingbirds: the impact of age, individual performance, and breeding site. Journal of Avian Biology 35:252-261.

Murphy, M. T, Cummings, C. L. \& Palmer, M. A. 1997. A comparative analysis of habitat selection, nest site and nest success by Cedar Waxwings and Eastern Kingbirds. American Midland Naturalist 138:344-356.

Newton, I. 1998. Population Limitation in Birds. New York: Academic Press. 
Olendorf, R., and S. K. Robinson. 2000. Effectiveness of nest defense in the Acadian Flycatcher Empidonax virescens. Ibis 142:365-371.

Pereyra, M. E. 2011. Effects of snow-related environmental variation in breeding schedules and productivity of a high-altitude population of Dusky Flycatchers (Empidonax oberholseri). Auk 128:746-758.

Putnam, L. S. 1949. The life history of the Cedar Waxwing. Wilson Bulletin 61:141182.

Redmond, L. J. \& Murphy, M. T. 2007. Unusual Barn Swallows nest placement in southeastern Oregon. Wilson Journal of Ornithology 119:307-309.

Redmond, L. J. \& Murphy, M. T. 2012. Using complementary approaches to estimate survival of juvenile and adult Eastern Kingbirds. Journal of Field Ornithology $83: 247-259$

Redmond, L. J., Murphy, M. T, \& Dolan, A. C. 2007. Nest reuse by Eastern Kingbirds: adaptive behavior or ecological constraint? Condor 109:463-468.

Redmond, L. J., Murphy, M. T, Dolan, A. C. \& Sexton, K. 2009a. Parental investment theory and nest defense by Eastern Kingbirds. Wilson Journal of Ornithology 121:1-11.

Redmond, L. J., Murphy, M. T., Dolan, A. C. \& Sexton, K. 2009b. Public information facilitates habitat selection of a territorial species: the eastern kingbird. Animal Behaviour 77:457-463. 
Rendell, W. B. \& Verbeek, N. A. M. 1996. Are avian ectoparasites more numerous in nest boxes with old nest materials? Canadian Journal of Zoology 74:1819-1825.

Richmond, S., Nol, E., Campbell, M. \& Burke, D. 2007. Conspecific and interspecific nest reuse by Wood Thrush (Hylocichla mustelina). Northeastern Naturalist 14:629-636.

Ricklefs, R. E. 1969. An analysis of nesting mortality in birds. Smithsonian Contributions to Zoology 9:1-48.

Ricklefs, R. E. 1977. Reactions of some Panamanian birds to human intrusion at the nest. Condor 79:376-379.

Safran, R. J. 2006. Nest-site selection in the barn swallow, Hirundo rustica: What predicts seasonal reproductive success. Canadian Journal of Zoology 84:15331539.

Sandercock, B. K., Lank, D. B. \& Cooke, F. 1999. Seasonal declines in the fecundity of artic-breeding sandpipers: different tactics in two species with an invariant clutch size. Journal of Avian Biology 30:460-468.

Santisteban, L. K.E. Sieving and M.L. Avery. 2002. Use of sensory cues by Fish Crows Corvus ossifragus preying on artificial bird nests. Journal of Avian Biology $33: 245-252$. 
Schoech, S. J. \& Hahn, T. P. 2008. Latitude affects degree of advancement in laying by birds in response to food supplementation: a meta-analysis. Oecologia 157:369376.

Siderius, J. A. 1993. Nest defense in relation to nesting stage and response of parents to repeated model presentations in the Eastern Kingbird (Tyrannus tyrannus). Auk 110:921-923.

Siegel-Causey, D. \& Hunt, G. L., Jr. 1986. Breeding-site selection and colony formation in Double-crested and Pelagic cormorants. Auk 103:230-234.

Siepielski, A. M., A. D. Rodewald and R. H. Yahner. 2001. Nest site selection and nesting success of the Red-eyed Vireo in central Pennsylvania. Wilson Bulletin 113:302-307.

Sonerud, G. A. \& Fjeld, P. E. 1987. Long-term memory in egg predators: An experiment with a Hooded Crow. Ornis Scandinavica 18:323-325.

Styrsky, J. N. 2005. Influence of predation on nest-site reuse by an open-cup nesting Neotropical passerine. Condor 107:133-137.

Vanderwerf, E. A. 2012. Evolution of nesting height in an endangered Hawaiian forest bird in response to a non-native predator. Conservation Biology 26:905-911.

Waters, J. R. \& Noon, B. R. 1990. Lack of nest site limitation in a cavity-nesting bird community. Journal of Wildlife Management 54:239-245. 
Walters, E. L., Miller, E. H, \& Lowther, P. E. 2002. Yellow-bellied Sapsucker (Sphyrapicus varius), The Birds of North America Online (A. Poole, Ed.). Ithaca: Cornell Lab of Ornithology http://bna.birds.cornell.edu.proxy.lib.pdx.edu/bna/species/662

Weeks, H. P., Jr. 1978. Clutch size variation in the Eastern Phoebe in southern Indiana. Auk 95:656-666.

Weidinger, K. 2002. Interactive effects of concealment, parental behaviour and predators on the survival of open passerine nests. Journal of Animal Ecology 71: 424-437.

Wilson, R. R. and R. J. Cooper. 1998. Acadian Flycatcher Nest Placement: Does Placement Influence Reproductive Success? Condor 100:673-679.

Wimberger, P. H. 1984. The use of green plant material in bird nests to avoid ectoparasites. Auk 101:615-618.

Withers, P. C. 1977. Energetic aspects of reproduction by the Cliff Swallow. Auk 94: $718-725$

Wysocki, D. 2004. Nest re-use by Blackbirds—The way for safe breeding? Acta Orithologica 39:164-168.

Zanette, L. Y., A. F. White, M. C. Allen, and M. Clinchy. 2011. Perceived predation risk reduces the number of offspring songbirds produce per year. Science $334: 1398-1401$. 